Research Article

\title{
Preparation and Photocatalytic Performance of ZnO/Sepiolite Composite Materials
}

\author{
Chao Li $(\mathbb{D}$, Huijuan Li $(\mathbb{D}$, Guicheng He, Zhiwu Lei, and Wenyuan Wu \\ School of Resources Environment and Safety Engineering, University of South China, Hengyang 421001, China \\ Correspondence should be addressed to Huijuan Li; huijuanli_2014@163.com
}

Received 21 April 2021; Accepted 31 May 2021; Published 17 June 2021

Academic Editor: Zhengyang Song

Copyright (c) 2021 Chao Li et al. This is an open access article distributed under the Creative Commons Attribution License, which permits unrestricted use, distribution, and reproduction in any medium, provided the original work is properly cited.

\begin{abstract}
Photocatalytic technology is a widely used water treatment method, whose efficiency can be increased by developing a suitable photocatalyst fabrication procedure. In this study, five different synthesis methods were utilised for the preparation of novel $\mathrm{ZnO} /$ sepiolite photolytic composites, namely, sol-gel method, hydrothermal reduction, hydrolytic precipitation, powder sintering, and impregnation-reduction. The obtained photocatalysts were characterised by scanning electron microscopy, infrared spectroscopy, and X-ray diffraction. The differences between the applied photocatalyst preparation methods and the reasons for these differences were discussed, and the photocatalytic activities of the prepared composite materials were compared. The obtained results revealed that the physical structure, chemical properties, and photocatalytic performance of the composite produced by the sol-gel method were superior to those of the materials fabricated by the other four methods. Moreover, this material also exhibited high photocatalytic stability, while its photocatalytic degradation of methylene blue dye proceeded via a quasi-first-order reaction. The prepared composites have broad application prospects in photocatalysis and can be potentially used for treating environmental pollutants.
\end{abstract}

\section{Introduction}

In 1977, Frank and Bard used $\mathrm{TiO}_{2}$ photocatalytic technology to treat $\mathrm{CN}^{-}$and $\mathrm{SO}_{3}{ }^{2-}$ plasmas, after which photocatalytic methods were successfully applied to control environmental pollution [1]. Photocatalytic materials typically include semiconductors such as metal oxide sulphides. Among various photocatalysts and their composites, $\mathrm{TiO}_{2}$ exhibits high and stable photocatalytic activity and, therefore, is commonly utilised in photocatalytic reactions. Some researchers studied [2-5] the photocatalytic performance of $\mathrm{TiO}_{2}$ for the treatment of aromatic hydrocarbon pollutants and methyl blue dye followed by its successful application in the degradation of landfill leachate. However, photocatalytic $\mathrm{TiO}_{2}$ pollution treatment technology has not been widely used in practical applications for the following reasons. (1) The adsorption capacity of $\mathrm{TiO}_{2}$ is relatively small, and the adsorbed species are difficult to separate in a liquid phase $[6,7]$. (2) $\mathrm{TiO}_{2}$ has a large bandgap, which can absorb not more than $4-5 \%$ of the ultraviolet (UV) light from the solar spectrum, while its spectral response range is narrow $[8,9]$.
(3) $\mathrm{TiO}_{2}$ particles easily agglomerate, which reduces their practicability $[10,11]$. Therefore, exploring other types of photocatalysts has recently become a hot research topic.

$\mathrm{ZnO}$ is a semiconductor with a forbidden band width of $3.37 \mathrm{eV}$ and exciton binding energy of $60 \mathrm{MeV}$ at room temperature, which is widely applied for the degradation of organic pollutants due to its excellent chemical stability, high photocatalytic activity, low fabrication cost, and other advantages [12-16]. The results of $\mathrm{ZnO}$-related studies revealed that the photocatalytic activity of zinc oxide was sufficiently high to decompose various pollutants in the environment [17]. For example, it can photocatalyse the degradation of harmful compounds $[18,19]$ such as aniline [20] under low UV light irradiation. In addition, $\mathrm{ZnO}$ may be doped by various compounds such as lanthanum and graphene [21, 22] that effectively photocatalyse the degradation of methyl orange and methylene blue (MB) dyes. However, the usability of $\mathrm{ZnO}$ in photocatalytic degradation applications has several limitations, including a wide bandgap $[23,24]$, high recombination rate of photogenerated electrons with holes, and low quantum efficiency $[25,26]$. To increase the photocatalytic efficiency of 
$\mathrm{ZnO}$ and expand the range of its spectral response to visible light, $\mathrm{ZnO}$ modification must be performed via metal/nonmetal ion doping and/or surface complexation reactions, which require the preparation of multiple composite materials.

\section{Literature Review}

The composite materials produced by various methods have different crystal structures, morphologies, optical properties, and photocatalytic efficiencies [27, 28]. Several researchers fabricated nanosized $\mathrm{TiO}_{2}$ powder [29] and $\mathrm{Sn}-\mathrm{Al}$ co-doped $\mathrm{ZnO}$ photocatalyst by sol-gel method [30]. The photocatalytic properties of the $\mathrm{Cu} / \mathrm{ZnO}$ catalysts prepared by hydrolysis method [31] and graphene- $\mathrm{ZnO}$ nanorod composites [32] were strongly influenced by the proportions of the raw materials; furthermore, the catalysts fabricated by different methods possessed different particle shapes and specific surface areas. For example, the Al-doped $\mathrm{ZnO}$ nanoparticles [33], $\mathrm{ZnO}$ nanoparticles [34, 35], and $\mathrm{CuO} /$ $\mathrm{ZnO}$ catalysts [36] prepared by the precipitation method showed that nanoparticle sizes could vary from several nanometres to several tens of nanometres under different experimental conditions and even reach hundreds of nanometres in the case of needle-like particles with various morphologies and degrees of cleanliness. The nanometresized zinc oxide powder synthesised by this method had pseudospherical particle shapes. In addition, a $\mathrm{ZnO} / \mathrm{ZnSe}$ composite with a maximum degradation rate of $91 \%$ was fabricated by a one-pot method [37], while $\mathrm{ZnO}$ nanoparticles were produced by a microwave method [38], and their crystal morphology was enhanced by optimising the solvent properties and crystal growth process.

In this study, sepiolite was used as a support for loaded $\mathrm{ZnO}$ particles. Because sepiolite is a hydrated magnesium silicate clay mineral with the largest specific surface area among nonmetallic minerals (up to $900 \mathrm{~m}^{2} / \mathrm{g}$ ), unique channel structure, high surface adsorption capacity, low weight, and high chemical stability, it can serve as the supporting material for the active photocatalyst components. To identify the best $\mathrm{ZnO} /$ sepiolite preparation method, the sepiolite support was modified by a thermal acid treatment, after which $\mathrm{ZnO} /$ sepiolite composite materials were fabricated by the sol-gel, hydrothermal reduction, hydrolytic precipitation, powder sintering, and impregnation-reduction methods. The obtained composites were characterised by scanning electron microscopy (SEM), infrared spectroscopy, and X-ray diffraction (XRD), and their photocatalytic properties were investigated.

\section{Experimental}

\subsection{Materials and Instruments}

3.1.1. Materials. The following materials were used: sepiolite raw ore, hydrochloric acid (analytical grade), sodium hexametaphosphate, distilled water, sodium hydroxide, zinc chloride, ethylene glycol, zinc acetate, anhydrous ethanol, ammonia solution, ice water, ammonium sulphate, silver nitrate, zinc oxide, zinc sulphate, hydrazine hydrate, and MB.
3.1.2. Instruments. The following instruments were used: vacuum filter extractor, 60 mesh sieve, 80 mesh sieve, constant temperature drying oven, muffle oven, X-ray powder diffractometer, scanning electron microscope, water bath, magnetic stirrer, vacuum filter extractor, hydrothermal reaction kettle, electronic scale, $\mathrm{pH}$ meter, $50 \mathrm{~W}$ highpressure mercury lamp, TGA-DSC/DTA synchronous thermal analyzer, UV-visible spectrophotometer.

\subsection{Sepiolite Modification Procedure}

3.2.1. Sepiolite Pretreatment. The raw sepiolite ore contained many impurities, including sepiolite, talc, calcite, and kaolinite, which required pretreatment. Briefly, $500 \mathrm{~g}$ of sepiolite was soaked in distilled water at a solid-liquid ratio of $1: 10$. After $24 \mathrm{~h}, 0.5 \mathrm{~g}$ of sodium hexametaphosphate was added to the obtained mixture, followed by settlement. The upper suspended matter was removed; it was then filtered under vacuum and placed into a drying oven at $105^{\circ} \mathrm{C}$. After drying for $24 \mathrm{~h}$, a sepiolite concentrate was obtained.

3.2.2. Thermal Acid Modification. In the next step, sepiolite was modified by a thermal acid treatment. After pretreatment, sepiolite was screened with 60 mesh and 80 mesh sieves, and the intermediate fraction was soaked for $6 \mathrm{~h}$ and filtered under vacuum. The obtained solid particles were repeatedly washed with distilled water to the neutral $\mathrm{pH}$, filtered, and placed into a drying oven at $105^{\circ} \mathrm{C}$. The produced sepiolite was annealed at $250^{\circ} \mathrm{C}$ in a muffle oven for $3 \mathrm{~h}$ and cooled to room temperature.

3.3. Preparation of $\mathrm{ZnO} /$ Sepiolite Composites. $\mathrm{ZnO} /$ sepiolite composite materials were prepared by the sol-gel, hydrothermal reduction, hydrolytic precipitation, powder sintering, and impregnation-reduction methods. The obtained composites were characterised by various techniques, and the loading degrees and morphologies of $\mathrm{ZnO}$ particles were determined.

3.3.1. Sol-Gel Method. Initially, $16 \mathrm{~g}$ of sodium hydroxide was added to a specified amount of glycol solution to achieve a final volume of $200 \mathrm{~mL}$. The resulting solution was placed on a magnetic stirrer and stirred until all sodium hydroxide particles were completely dissolved to obtain a $2 \mathrm{~mol} / \mathrm{L}$ sodium hydroxide solution in ethylene glycol (solution A). Afterwards, $27.26 \mathrm{~g}$ of zinc chloride was added to the ethylene glycol solution to achieve a final volume of $200 \mathrm{~mL}$. The resulting mixture was placed on a magnetic stirrer and stirred until all zinc chloride particles were completely dissolved to obtain a $1 \mathrm{~mol} / \mathrm{L}$ zinc chloride solution in ethylene glycol (solution B). After mixing solutions A and B, the produced mixture was stirred for $30 \mathrm{~min}$ to obtain a precursor of zinc oxide sol, which was placed in a water bath with a temperature of $95^{\circ} \mathrm{C}$ for $3 \mathrm{~h}$ to produce zinc oxide sol. Finally, $16.26 \mathrm{~g}$ of the activated and modified sepiolite was added to the sol, stirred at room temperature for $1 \mathrm{~h}$, heated in a water bath at $80^{\circ} \mathrm{C}$ until it became almost dry, cooled, 
and dried in a drying oven at $80^{\circ} \mathrm{C}$. The obtained product was placed into a muffle furnace and heated to $450^{\circ} \mathrm{C}$. After continuous annealing for $4 \mathrm{~h}$, the solid was taken out of the furnace and cooled to room temperature to obtain a $\mathrm{ZnO} /$ sepiolite composite material.

3.3.2. Hydrothermal Reduction Method. First, $4.51 \mathrm{~g}$ of zinc acetate was mixed with $20 \mathrm{~mL}$ of distilled water and $60 \mathrm{~mL}$ of anhydrous ethanol. The resulting mixture was stirred until all zinc acetate particles were completely dissolved followed by the addition of $2 \mathrm{~g}$ of modified sepiolite and continuous stirring for $30 \mathrm{~min}$. After that, $8 \mathrm{~mL}$ of ammonia solution was diluted with $20 \mathrm{~mL}$ of anhydrous ethanol, and the obtained product was added dropwise to the mixture. The latter was stirred for $1 \mathrm{~h}$, transferred to a $200 \mathrm{~mL}$ hydrothermal reaction kettle, and heated to $120^{\circ} \mathrm{C}$ for $5 \mathrm{~h}$. Subsequently, the reaction mixture was taken out of the kettle and placed into a drying oven with a temperature of $105^{\circ} \mathrm{C}$. The dry product was heated in a muffle furnace at $450^{\circ} \mathrm{C}$ for $4 \mathrm{~h}$ and then cooled down to room temperature to obtain a $\mathrm{ZnO} /$ sepiolite composite.

3.3.3. Hydrolytic Precipitation Method. First, ice was crushed with an ice breaker. Then, $200 \mathrm{~mL}$ of distilled water was added to $20 \mathrm{~g}$ of sepiolite to achieve a solid-to-liquid mass ratio of $1: 10$. After mixing, the solution was placed into an ice water bath followed by the addition of $1 \mathrm{~mL}$ of pure hydrochloric acid. In the next step, $25.215 \mathrm{~g}$ of zinc chloride was weighted and dissolved in an appropriate amount of distilled water and then transferred to a volumetric flask with a constant volume of $50 \mathrm{~mL}$ to obtain a $3.7 \mathrm{~mol} / \mathrm{L}$ zinc chloride solution. Subsequently, $19.8 \mathrm{~g}$ of ammonium sulphate was dissolved in an appropriate amount of distilled water and transferred to a volumetric flask with a constant volume of $100 \mathrm{~mL}$ to obtain a $1.5 \mathrm{~mol} /$ $\mathrm{L}$ ammonium sulphate solution. The prepared zinc chloride solution was added to the first solution. After $10 \mathrm{~min}, 10 \mathrm{~mL}$ of the ammonium sulphate solution was added to the reaction mixture, which was then stirred for $10 \mathrm{~min}$ and heated to $80^{\circ} \mathrm{C}$ for $1 \mathrm{~h}$ in a water bath. The mixture was the neutralised with ammonia solution to $\mathrm{pH}=6$, stored for $1 \mathrm{~h}$, washed with distilled water, and filtered. Finally, $3.397 \mathrm{~g}$ of silver nitrate was dissolved in an appropriate amount of distilled water and transferred to a $200 \mathrm{~mL}$ volumetric flask to obtain a $0.1 \mathrm{~mol} / \mathrm{L}$ silver nitrate solution. After detecting free chloride ions in the reaction mixture with this solution, the fabricated sample was dried in a drying oven at $105^{\circ} \mathrm{C}$, heated to $450^{\circ} \mathrm{C}$ for $2.5 \mathrm{~h}$ in a muffle furnace, and cooled down to room temperature to obtain a $\mathrm{ZnO} /$ sepiolite composite.

3.3.4. Powder Sintering Method. After mixing $5 \mathrm{~g}$ of zinc oxide with $5 \mathrm{~g}$ of sepiolite, a certain amount of anhydrous ethanol was added to the obtained mixture to fully wet the solid particles, which were subsequently ground for $30 \mathrm{~min}$. The resulting mixture was placed into a muffle furnace and continuously annealed at $300^{\circ} \mathrm{C}$ for $6 \mathrm{~h}$. After cooling to room temperature, the sample was ground until its particle sizes became uniform to obtain a $\mathrm{ZnO} /$ sepiolite composite material.

3.3.5. Impregnation-Reduction Method. First, $12 \mathrm{~g}$ of sodium hydroxide was dissolved in an appropriate amount of distilled water and then transferred to a volumetric flask with a constant volume of $50 \mathrm{~mL}$ to obtain a $6 \mathrm{~mol} / \mathrm{L}$ sodium hydroxide solution. Next, $100 \mathrm{~mL}$ of the hydrazine hydrate solution was diluted to $514.3 \mathrm{~mL}$ to obtain a $2 \mathrm{~mol} / \mathrm{L}$ hydrazine solution. Subsequently, $16.144 \mathrm{~g}$ of zinc sulphate was added to $400 \mathrm{~mL}$ of deionized water. After all zinc sulphate species were completely dissolved, $8.138 \mathrm{~g}$ of sepiolite was added to the mixture, which was then stirred for $30 \mathrm{~min}$ using a magnetic stirrer. During this process, $5 \mathrm{~mL}$ of the $6 \mathrm{~mol} / \mathrm{L}$ sodium hydroxide solution was added to the reaction system. After continuous stirring for $30 \mathrm{~min}, 3 \mathrm{~mL}$ of the $2 \mathrm{~mol} / \mathrm{L}$ hydrazine solution was added dropwise, and after 10 minutes of reaction, $0.015 \mathrm{~mol}$ of ammonia $(2.25 \mathrm{~mL}$ of the concentrated ammonia solution) was added to the mixture. The subsequent reaction was performed at room temperature for $3 \mathrm{~h}$. A $\mathrm{ZnO} /$ sepiolite composite was obtained by washing the resulting solid with deionized water three times and then with anhydrous ethanol three times. The composite was annealed in a muffle furnace at $450^{\circ} \mathrm{C}$ for $3 \mathrm{~h}$ and then cooled down to room temperature.

3.4. Photocatalytic Performance Testing. To investigate the photocatalytic properties of the produced composites, the photocatalytic degradation of $\mathrm{MB}$ was performed at room temperature under simulated UV light irradiation with a power of $50 \mathrm{~W}$ using a high-pressure mercury lamp. In selected reactions, $20 \mathrm{mg}$ of the photocatalyst was dispersed in $100 \mathrm{~mL}$ of the $\mathrm{MB}$ aqueous solution $(0.015 \mathrm{~g} / \mathrm{L})$ under magnetic agitation. In all photodegradation experiments, the distance between the experimental device and the light source was $7 \mathrm{~cm}$. Before the photodegradation experiment, the catalyst-dye mixture was stirred in the dark for $1 \mathrm{~h}$ to reach an adsorption-desorption equilibrium. Afterwards, the mixture was exposed to the light generated by the highpressure mercury lamp and continuously stirred. During the reaction, $3 \mathrm{~mL}$ of the mixture was taken out every $10 \mathrm{~min}$, after which the catalyst was removed by centrifugation, and the change in absorbance was measured by the UV-Vis spectrophotometer. The reusability and photostability of the composite with the best photocatalytic performance were evaluated during the first five MB degradation cycles. Finally, the photocatalytic mechanism of the composite was analyzed, and the methods to improve the photocatalytic effect were proposed.

\section{Results and Discussion}

4.1. Morphological Analysis. Each analyzed sample was attached to a piece of copper sheet with conductive tape, sprayed with gold, and placed on the sample holder for SEM testing. Figures 1and 2 display the SEM images of sepiolite obtained before and after thermal acid modification. 


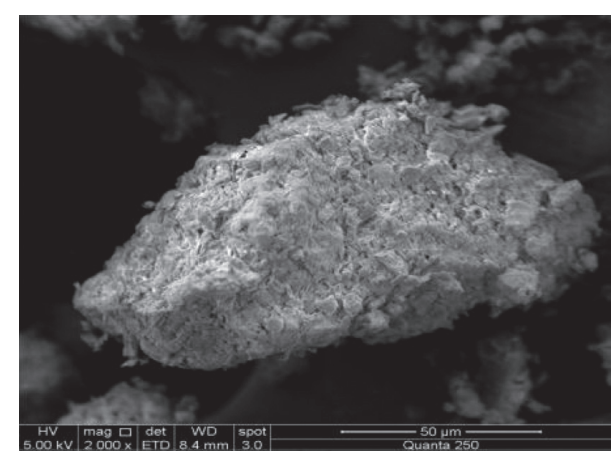

FIGURE 1: SEM image of the nonmodified sepiolite.

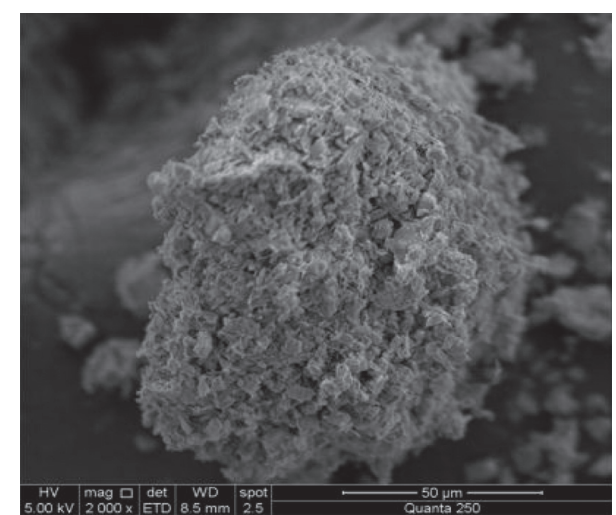

FIGURE 2: SEM image of the modified sepiolite.

The figures show that the modified sepiolite has a higher specific surface area, larger surface pores, and looser structure as compared with those of the nonmodified sepiolite. Moreover, it likely exhibits higher catalytic activity and higher degree of immobilisation of $\mathrm{ZnO}$ particles.

The SEM image of the $\mathrm{ZnO} /$ sepiolite composite prepared by the sol-gel method is shown in Figure 3. In contrast to Figure 2, the composite surface is completely covered by the layer of a gel-like material consisting of the loaded zinc oxide gel obtained from the sol precursor. These results indicate that zinc oxide has successfully adhered to the sepiolite surface.

The SEM image of the composite prepared by the hydrothermal reduction method is presented in Figure 4. Similar to Figure 3, the sepiolite surface is covered with some material. In the hydrothermal reduction method, a zinc salt is crystallised on sepiolite under hydrothermal conditions and then decomposed into a metal oxide at a high temperature. As a result, zinc ions are loaded on the sepiolite surface in the form of crystals and then oxidised to produce zinc oxide. Therefore, the material deposited on the sepiolite surface consists of zinc oxide; however, its particle distribution is not uniform.

The SEM image of the $\mathrm{ZnO}$ /sepiolite composite fabricated by the hydrolytic precipitation method is displayed in Figure 5. It shows a layer of fine particles with a relatively large mass attached to the sepiolite surface; however, their distribution is not uniform.

The SEM image of the composite prepared by the powder sintering method is shown in Figure 6. In this image, the

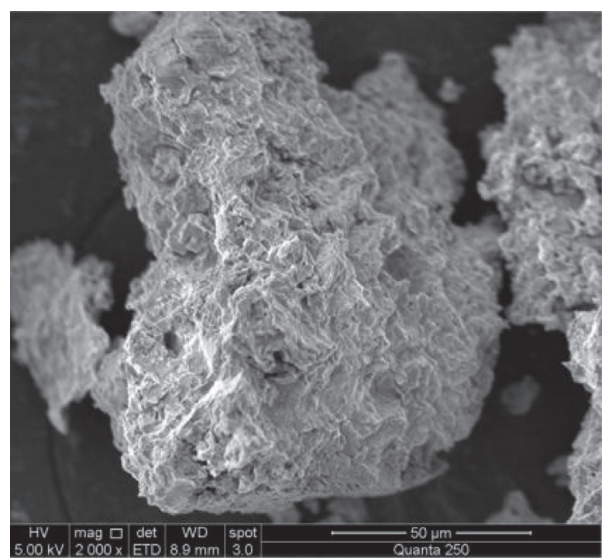

FIGURE 3: SEM image of the $\mathrm{ZnO} /$ sepiolite composite prepared by the sol-gel method.

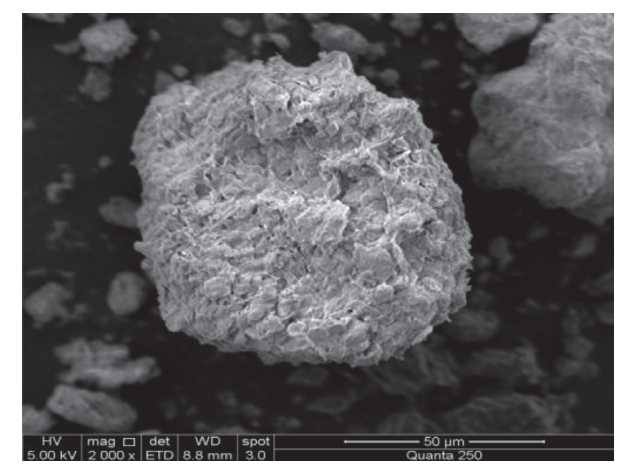

FIGURE 4: SEM image of the $\mathrm{ZnO}$ /sepiolite composite prepared by the hydrothermal reduction method.

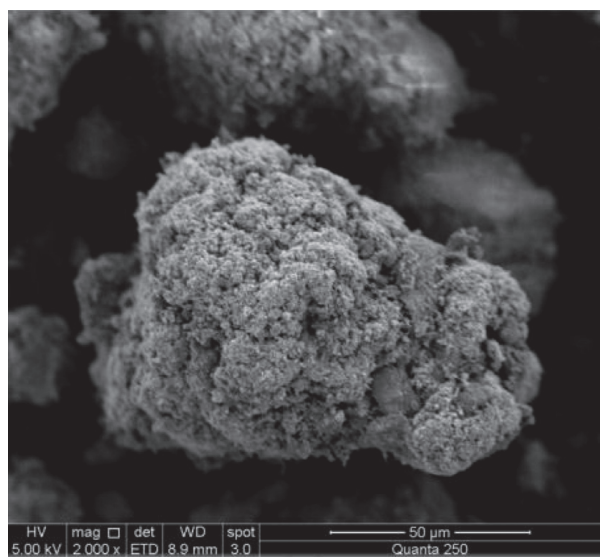

FIGURE 5: SEM image of the $\mathrm{ZnO} /$ sepiolite composite prepared by the hydrolytic precipitation method.

sepiolite surface is coated by the fine $\mathrm{ZnO}$ particles with an average loading; however, their distribution is more uniform than that of the particles prepared by the hydrolytic precipitation method.

The SEM image of the $\mathrm{ZnO} /$ sepiolite composite fabricated by the impregnation-reduction method is presented in Figure 7. It shows that the coated particles have a large load and uniform distribution. Here, zinc oxide is attached to the 


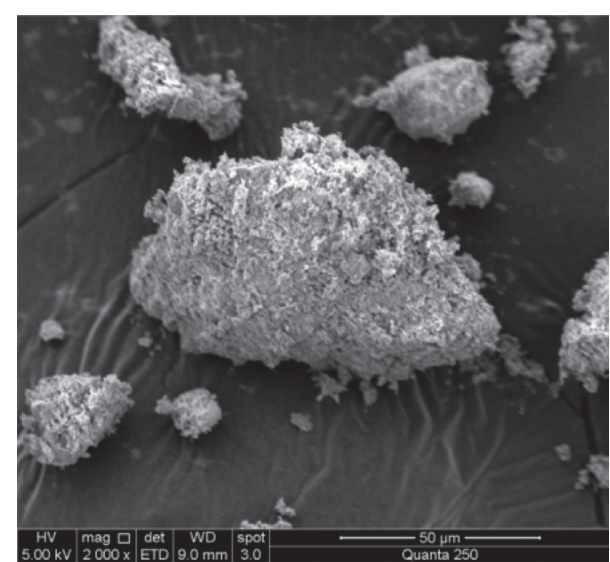

FIGURE 6: SEM image of the $\mathrm{ZnO} /$ sepiolite composite prepared by the powder sintering method.

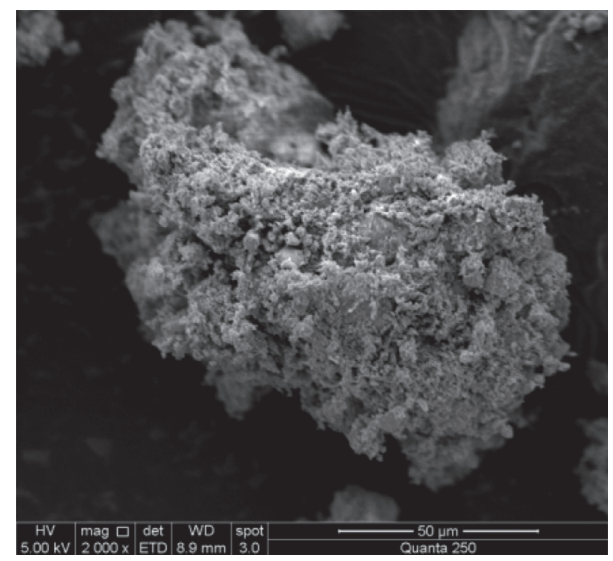

Figure 7: SEM image of the $\mathrm{ZnO} /$ sepiolite composite prepared by the impregnation-reduction method.

sepiolite surface in the form of small particles with a large specific surface area, containing many catalytically active sites. The composite prepared by this method retained the large specific surface area; however, a significant fraction of zinc oxide particles precipitated and aggregated on the sepiolite surface.

4.2. Spectral Analysis. A sample was evenly mixed with potassium bromide and pressed into tablets. Its infrared spectrum was recorded by an infrared spectrometer.

Figure 8 shows the infrared spectrogram of sepiolite, which contains the characteristic peaks of its various groups. In the high-frequency region, the absorption band at $2900-3700 \mathrm{~cm}^{-1}$ is generated by the stretching vibration of the $\mathrm{OH}$ group; the absorption band at $3676.32 \mathrm{~cm}^{-1}$ is produced by the stretching vibration of the $\mathrm{Mg}-\mathrm{OH}$ group; and the characteristic peak of crystal water is centred at $3564.45 \mathrm{~cm}^{-1}$. This peak belongs to the $\mathrm{H}-\mathrm{O}-\mathrm{H}$ bending deformation vibration zone located between 1400 and $1700 \mathrm{~cm}^{-1}$ and has a relatively high intensity. In the range of $900-1300 \mathrm{~cm}^{-1}$, there is a strong absorption band caused by the stretching vibration of the Si-O bond. In addition, the characteristic calcite peak is located between 600 and
$800 \mathrm{~cm}^{-1}$. In the $400-600 \mathrm{~cm}^{-1}$ region, a strong bending deformation of the $\mathrm{Si}-\mathrm{O}$ bond is observed.

Figure 9 displays the infrared spectrum of the modified sepiolite. In this sample, magnesium ions leached due to their substitution with hydrogen ions. As compared with Figure 8 , the absorption peak centred at $3564.45 \mathrm{~cm}^{-1}$ is enhanced, and the peak at $3676.32 \mathrm{~cm}^{-1}$ is significantly weakened. Because calcite reacts with hydrochloric acid to produce carbon dioxide, the three absorption peaks in the $600-800 \mathrm{~cm}^{-1}$ region were transformed into two peaks, and the calcite characteristic peaks disappeared. Owing to the high-temperature annealing and activation processes, water was desorbed from the sepiolite surface; as a result, the characteristic peak at $1425.40 \mathrm{~cm}^{-1}$ disappeared. Meanwhile, the peak intensities in the low-frequency region did not change significantly after modification. Hence, the thermal acid treatment removed some magnesium ions, carbonate impurities, and adsorbed water from the sepiolite surface. Figure 10 shows the infrared spectrum of zinc oxide.

According to literature data, the absorption peak at $3427.51 \mathrm{~cm}^{-1}$ is the characteristic peak of the $\mathrm{O}-\mathrm{H}$ bonds in physisorbed water molecules. The characteristic absorption peak of the nanosized zinc oxide is located between 400 and $600 \mathrm{~cm}^{-1}$ [39].

Figures 11-15 display the infrared spectra of the $\mathrm{ZnO} /$ sepiolite composites prepared by the sol-gel, hydrothermal reduction, hydrolytic precipitation, powder sintering, and impregnation-reduction methods, respectively.

The figures show that the wavelength range of the zinc oxide characteristic peak overlaps with that of sepiolite, which has a certain influence on the conclusion of the loading condition of zinc oxide on sepiolite. However, the zinc oxide loading on the sepiolite surface can be determined from the intensity variations of the characteristic absorption peaks located between 400 and $600 \mathrm{~cm}^{-1}$. The infrared spectrum of the composite sample obtained by the hydrothermal reduction method has the largest variation range of these peaks in the specified region followed by the spectra of the $\mathrm{ZnO} /$ sepiolite composites prepared by powder sintering, impregnation-reduction, and sol-gel methods.

4.3. Structural Analysis. In this paper, 100 mesh sepiolite from Xiangtan sepiolite Technology Co., Ltd., was selected, and the chemical formula was $\mathrm{Mg}_{8}\left(\mathrm{H}_{2} \mathrm{O}\right)_{4}\left(\mathrm{Si}_{6} \mathrm{O}_{10}\right)_{2}$ $(\mathrm{OH})_{4} \cdot 8 \mathrm{H}_{2} \mathrm{O}$. The theoretical chemical composition is $\mathrm{MgO}=21 \%-25 \% ; \mathrm{SiO}_{2}=54 \%-60 \%$. There is also a small number of exchange cations, the charge for the tetrahedral weight of the ion exchange produced. $\mathrm{Si}^{4+}$ in tetrahedron can be replaced by $\mathrm{Fe}^{3+}$ and $\mathrm{Al}^{3+}$, the $\mathrm{Mg}^{2+}$ in octahedron can be replaced by $\mathrm{Mn}^{2+}, \mathrm{Fe}^{2+}$ or $\mathrm{Fe}^{3+}$. XRD analysis shows that $\mathrm{SiO}_{2}$ content is high, containing $\mathrm{Fe}, \mathrm{K}, \mathrm{Ca}$ and other impurities. The spectral analysis results of sepiolite are shown in Table 1.

In Figure 16, the XRD analysis of sepiolite ore samples, the value of $2 \theta$ at $7.4^{\circ}$ is the diffraction peak of sepiolite on plane 110 , the $2 \theta$ values at $26.7^{\circ}$ and $9.3^{\circ}$ are characteristic diffraction peaks of quartz and talc, respectively, the diffraction peak of impurity calcite is $2 \theta$ at $29.59^{\circ}$, and the main 


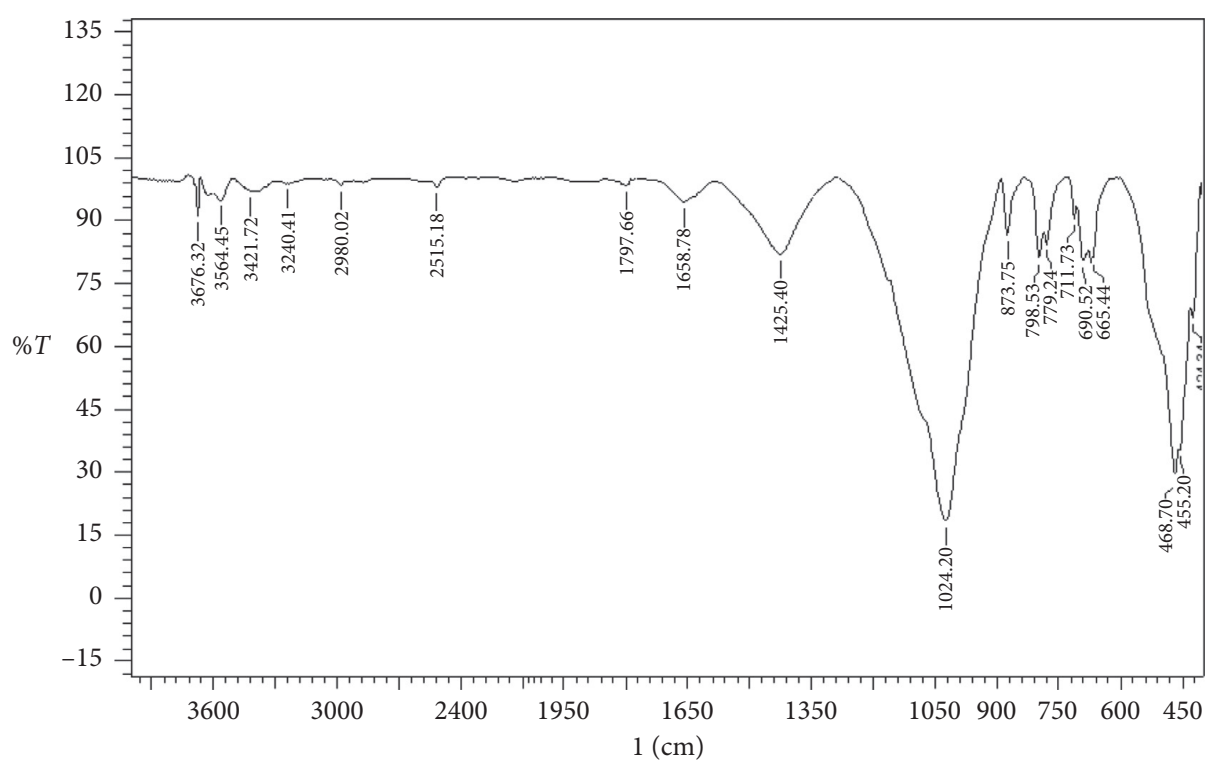

FIGURE 8: Infrared spectrum of sepiolite.

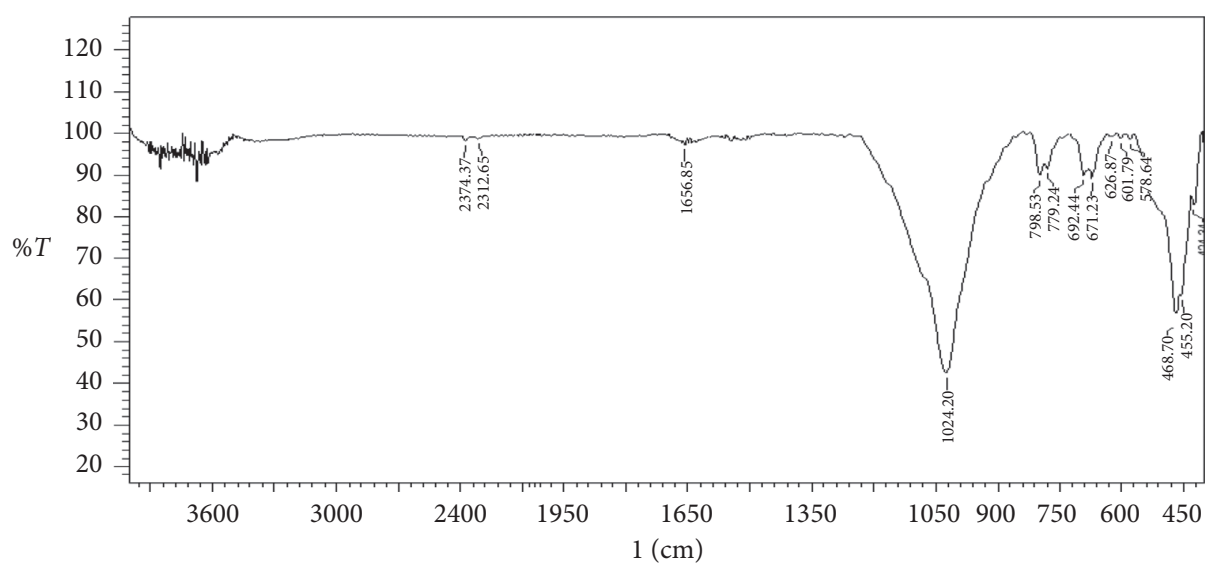

Figure 9: Infrared spectrum of the modified sepiolite.

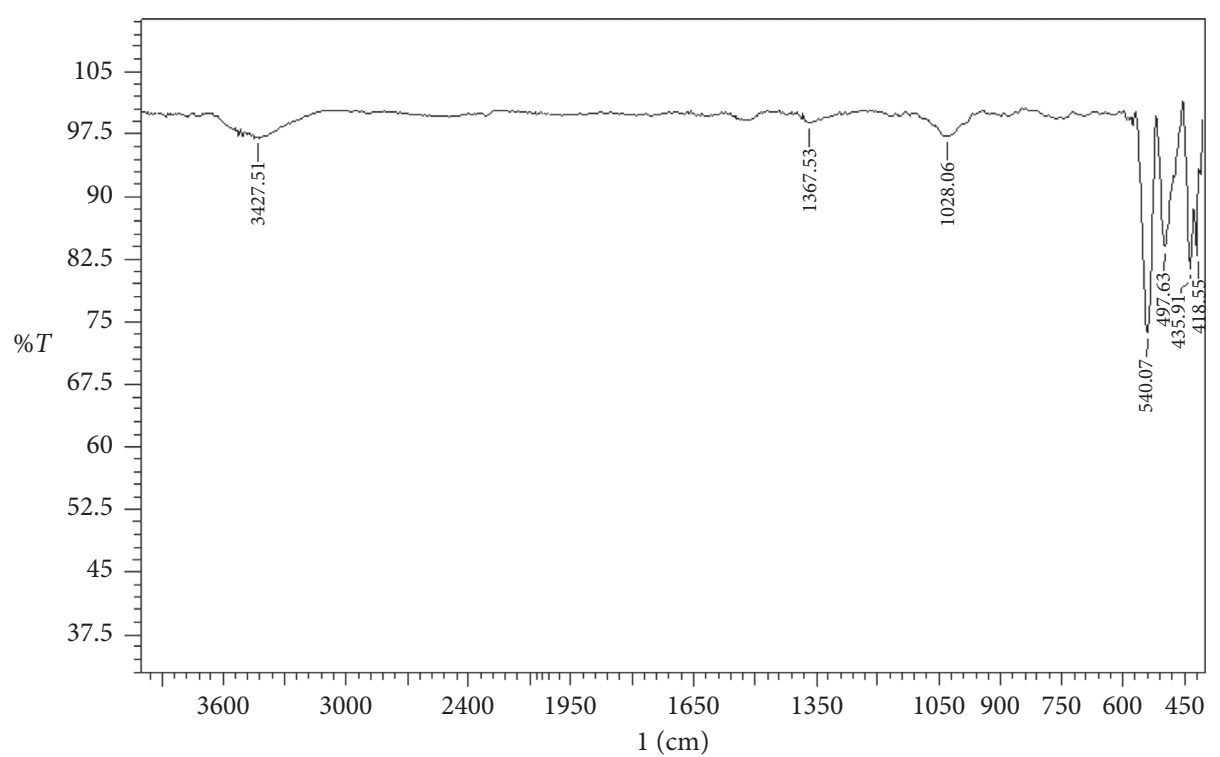

Figure 10: Infrared spectrum of $\mathrm{ZnO}$. 


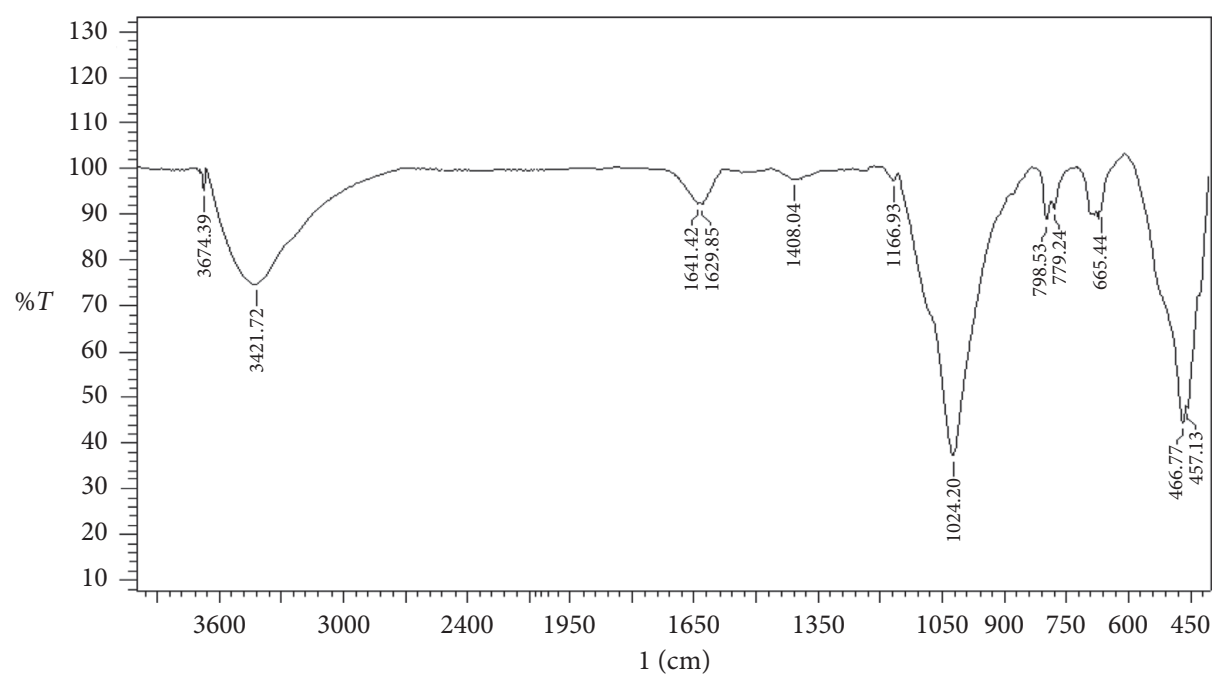

Figure 11: Infrared spectrum of the $\mathrm{ZnO} /$ sepiolite composite prepared by the sol-gel method.

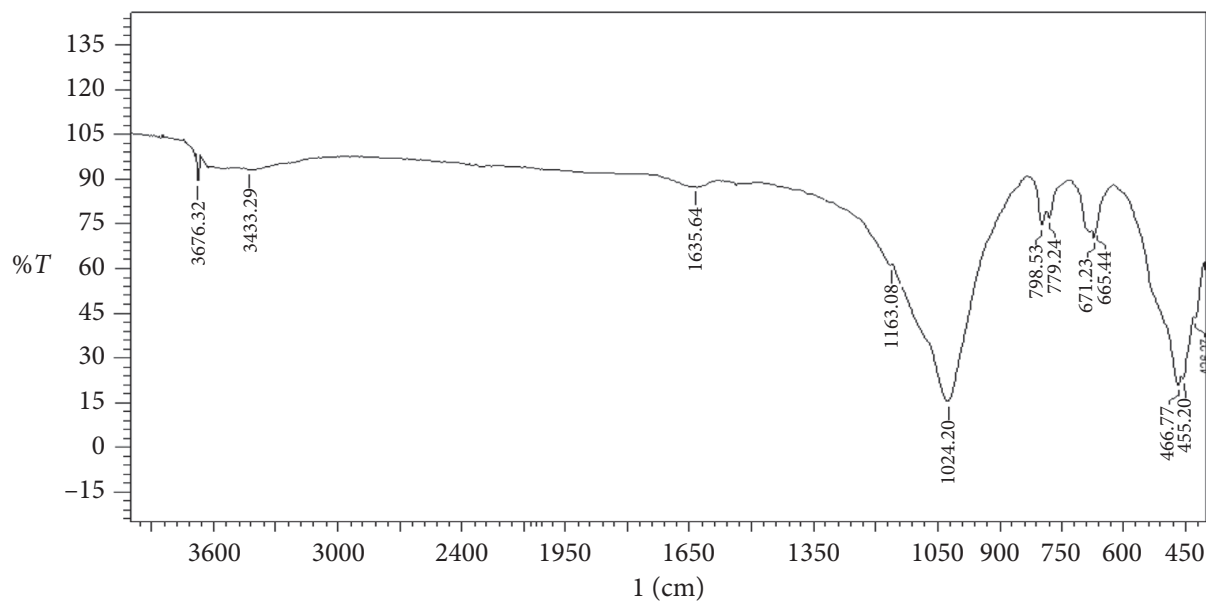

Figure 12: Infrared spectrum of the $\mathrm{ZnO}$ /sepiolite composite prepared by the hydrothermal reduction method.

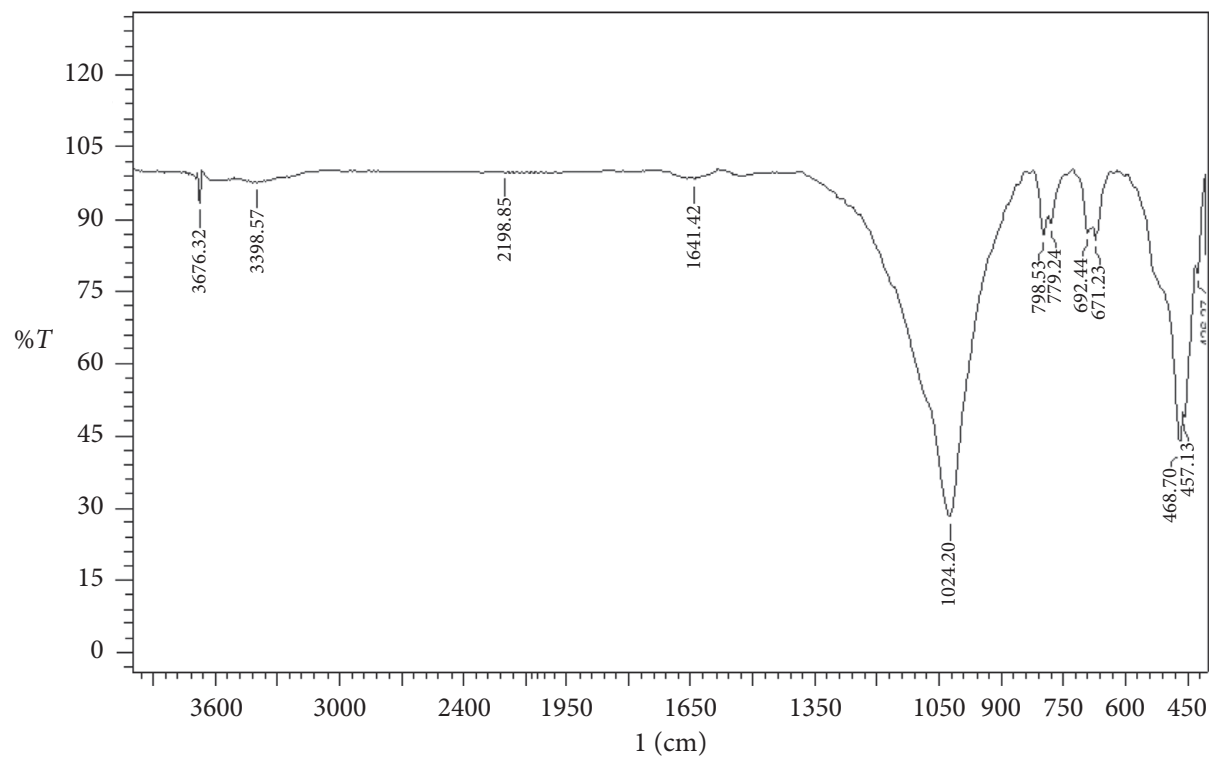

FIGURE 13: Infrared spectrum of the $\mathrm{ZnO} /$ sepiolite composite prepared by the hydrolytic precipitation method. 


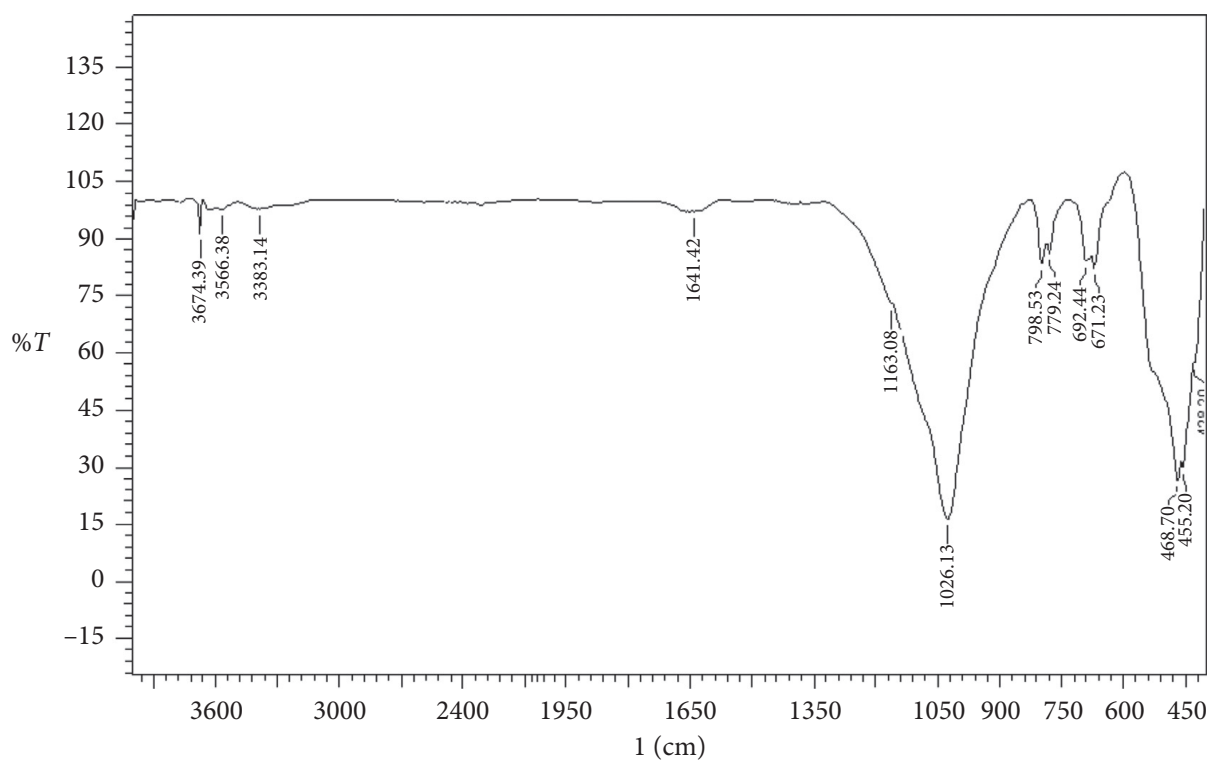

Figure 14: Infrared spectrum of the $\mathrm{ZnO} /$ sepiolite composite prepared by the powder sintering method.

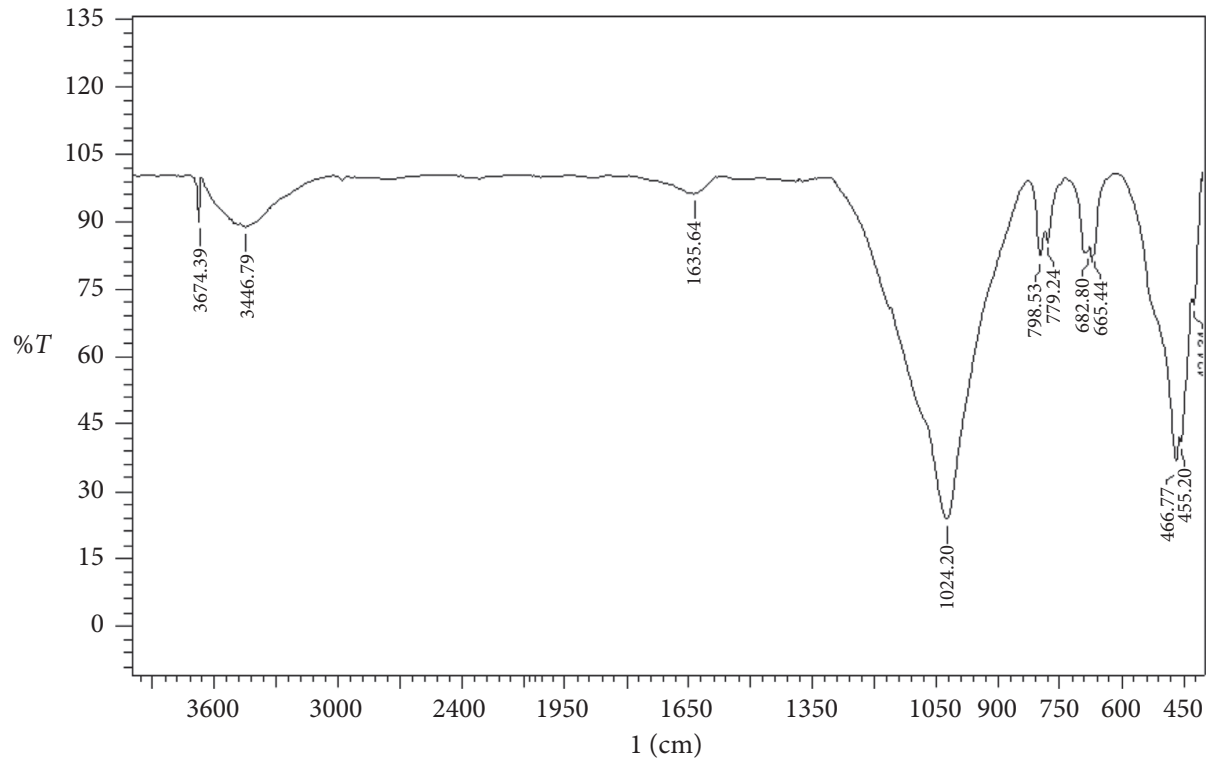

FIGURE 15: Infrared spectrum of the $\mathrm{ZnO} /$ sepiolite composite prepared by the impregnation-reduction method.

TABLE 1: Results of X-ray fluorescence spectrum analysis of sepiolite (measuring unit: $\omega(\mathrm{B}) / 10^{-2}$ ).

\begin{tabular}{lccccccccccc}
\hline Ingredient & $\mathrm{SiO}_{2}$ & $\mathrm{AI}_{2} \mathrm{O}_{3}$ & $\mathrm{Fe}_{2} \mathrm{O}_{3}$ & $\mathrm{MgO}$ & $\mathrm{CaO}$ & $\mathrm{Na}_{2} \mathrm{O}$ & $\mathrm{K}_{2} \mathrm{O}$ & $\mathrm{MnO}$ & $\mathrm{TiO}_{2}$ & $\mathrm{P}_{2} \mathrm{O}_{5}$ & Loss on ignition \\
\hline Content & 64.45 & 7.32 & 2.50 & 12.10 & 4.55 & 0.15 & 0.42 & 0.05 & 0.21 & 0.05 & 8.20 \\
\hline
\end{tabular}

components of crystal are sepiolite, quartz, talc, and calcite. Calculate according to XRD software, $41.9 \%$ of sepiolite, $31.1 \%$ of quartz, $12.8 \%$ of talc, $14.1 \%$ of calcite; it indicates that the impurities in the original sepiolite ore used in this study are mainly quartz, calcite, and a small amount of talc.

The density of quartz is $2.65 \mathrm{~g} / \mathrm{cm}^{3}$, that of sepiolite is $2.03 \mathrm{~g} / \mathrm{cm}^{3}$, after purification by precipitation, and the diffraction peaks of sepiolite are enhanced, while those of quartz and talc are weakened. In Figure 17, calculated by $\mathrm{XRD}$, the sepiolite content increased from $41.9 \%$ to $72 \%$, quartz content decreased from $31.1 \%$ to about $10 \%$, talc from $12.8 \%$ to $5 \%$; it shows that the impurities are basically removed after purification and the purpose of purification is achieved.

Figures 16 and 18 display the XRD patterns of the nonmodified and modified sepiolite, respectively. They show that the spectrum of modified sepiolite lacks the calcite peak; in addition, the peaks corresponding to the other impurities either decreased in intensity or disappeared completely, while the intensity of the sepiolite peak increased from 
approximately 800 to about 950 after modification because hydrogen ions replaced magnesium ions in the sepiolite structure after the acid treatment, and the grain shape was good. After modification, the sepiolite characteristic peak shifted to a lower angle, indicating that both the pore size and specific surface area of sepiolite increased. The TGA/ DTA test results of sepiolite are shown in Figure 19.

The experimental results show that the structure of sepiolite does not change from room temperature to $300^{\circ} \mathrm{C}$, which is mainly due to the process of water desorption. The structure of sepiolite changes at $300 \sim 800^{\circ} \mathrm{C}$, which is a process of decrystallising water, the sepiolite loses crystal water and forms anhydrous sepiolite phase, and its structure is locally adjusted. At $800 \sim 1000^{\circ} \mathrm{C}$ stage, the mineral composition of sepiolite is recombined and its structure is completely destroyed; the main process of dehydroxy water resulted in the formation of new mineral facies calcite and enstatite. Therefore, the thermal stability of sepiolite is better than other clay minerals, and good thermal stability is the premise of sepiolite as raw material for the preparation of composite materials.

Figure 20 depicts the XRD pattern of zinc oxide, which is consistent with the hexagonal wurtzite $\mathrm{ZnO}$ structure. No impurities were detected in the zinc oxide sample. The observed XRD peak is sharp and exhibits a relatively high intensity, which indicates a high degree of crystallinity. However, some widening was observed in the lower part of the diffraction peak, suggesting that $\mathrm{ZnO}$ grains were refined, which was consistent with the particle characteristics.

Figures 21-25 show the XRD patterns of the $\mathrm{ZnO} / \mathrm{se}$ piolite composites prepared by the sol-gel, hydrothermal reduction, hydrolytic precipitation, powder sintering, and impregnation-reduction methods, respectively. All these patterns exhibit smaller characteristic sepiolite peaks (as compared with those in the pure sepiolite spectra) as well as the characteristic peaks of anatase and zinc oxide. These phenomena indicate that the material deposited on the sepiolite surface consists of zinc oxide. Furthermore, the zinc oxide diffraction peaks of the composites prepared by the sol-gel method, hydrothermal reduction, and powder sintering methods are relatively strong and exhibit good shapes, whereas the $\mathrm{ZnO}$ peaks of the materials prepared by the other methods are relatively weak. The main $\mathrm{ZnO}$ /sepiolite composite characteristics are summarised in Table 2.

4.4. Photocatalytic Performance. To evaluate the photocatalytic performance of the fabricated composites, the $\mathrm{ZnO} /$ sepiolite composites and $\mathrm{ZnO}$ were applied to degrade organic pollutant MB. First, the catalytic material and MB were continuously stirred in the dark for $1 \mathrm{~h}$ to reach an adsorption-desorption equilibrium. The absorbance of the obtained solution was measured after centrifugation under UV irradiation at different intervals using the high-pressure mercury lamp. The observed variation of $\mathrm{MB}$ concentration with exposure time is shown in Figure 26. The absorption intensity of the raw $\mathrm{MB}$ (without $\mathrm{ZnO}$ or $\mathrm{ZnO} /$ sepiolite composites) exposed to UV-Vis light decreased only slightly, indicating that very little MB amount degraded under UV light irradiation in the absence of a catalyst (the corresponding degradation rate was only 6.5\%). With the addition of $\mathrm{ZnO}$ or the $\mathrm{ZnO} /$ sepiolite composite materials, the $\mathrm{MB}$ concentration decreased with an increase in the irradiation time, suggesting that all these materials exhibited high photocatalytic activity for the $\mathrm{MB}$ degradation. The $\mathrm{ZnO} /$ sepiolite composite prepared by the sol-gel method degraded approximately $93.5 \%$ of the initial $\mathrm{MB}$ amount within $90 \mathrm{~min}$, while the degradation rate of $\mathrm{MB}$ over $\mathrm{ZnO}$ catalyst was only $81 \%$. Therefore, the catalytic activity of the $\mathrm{ZnO} /$ sepiolite composite for $\mathrm{MB}$ photodegradation was superior to that of $\mathrm{ZnO}$ catalyst.

The obtained experimental data were fitted with the following equation derived for the first-order reaction kinetic model:

$$
\begin{aligned}
\frac{-\mathrm{d} C}{\mathrm{~d} t} & =k \times C, \\
-\ln \left(\frac{C}{C_{0}}\right) & =K \times t, \\
\ln \left(\frac{C_{0}}{C}\right) & =k \times t .
\end{aligned}
$$

Here, $C_{0}$ is the initial $\mathrm{MB}$ concentration, $C$ is the $\mathrm{MB}$ concentration measured after a 10-minute interval, $t$ is the irradiation time, and $K\left(\mathrm{~min}^{-1}\right)$ is the first-order rate constant. Figure 27 shows the linear relationship between $\ln \left(C_{0} /\right.$ $C$ ) and degradation time $(t)$ under UV irradiation. After the addition of the $\mathrm{ZnO}$ /sepiolite composite prepared by the solgel method, the first-order rate constant of $\mathrm{MB}$ degradation was $K=0.03722 \mathrm{~min}^{-1}$. Without the addition of a photocatalyst, its value was $k=0.00061 \mathrm{~min}^{-1}$. Finally, after the $\mathrm{ZnO}$ addition, the first-order rate constant of $\mathrm{MB}$ degradation was $K=0.013889 \mathrm{~min}^{-1}$. The obtained $R^{2}$ values exceeded 0.9; hence, the photocatalytic degradation of $\mathrm{MB}$ was a quasi-first-order reaction.

The reusability and photostability of the $\mathrm{ZnO}$ /sepiolite composite, containing $100 \mathrm{mg}$, prepared by the sol-gel method were studied as well. In this experiment, five $\mathrm{MB}$ degradation cycles were performed. After each cycle, the utilised composite was collected and washed for the next degradation cycle. The obtained powder was dried at $60^{\circ} \mathrm{C}$ for $12 \mathrm{~h}$. The photodegradation efficiencies of the $\mathrm{ZnO} / \mathrm{se}-$ piolite composite measured during the five degradation cycles are shown in Figure 28 (their values are equal to $93.5 \%, 90.9 \%, 88.7 \%, 86.1 \%$, and $85.8 \%)$. These results indicate that the $\mathrm{ZnO}$ /sepiolite composite prepared by the solgel method exhibits excellent reusability and photostability properties, which can be attributed to its high chemical stability and photoelectric performance.

The phase structure of the composites after recycling was analyzed by XRD to observe whether the material structure changes after photocatalytic reaction.

As shown in Figure 29, the XRD pattern of the catalyst after repeated use was basically the same as the composition of the original compound. It shows that $\mathrm{ZnO}$ is well loaded on the sepiolite surface and the bond is firm. Therefore, $\mathrm{ZnO} /$ sepiolite composite is a kind of photocatalytic composite material with stable chemical properties, easy to be separated, and easy to be recycled. 


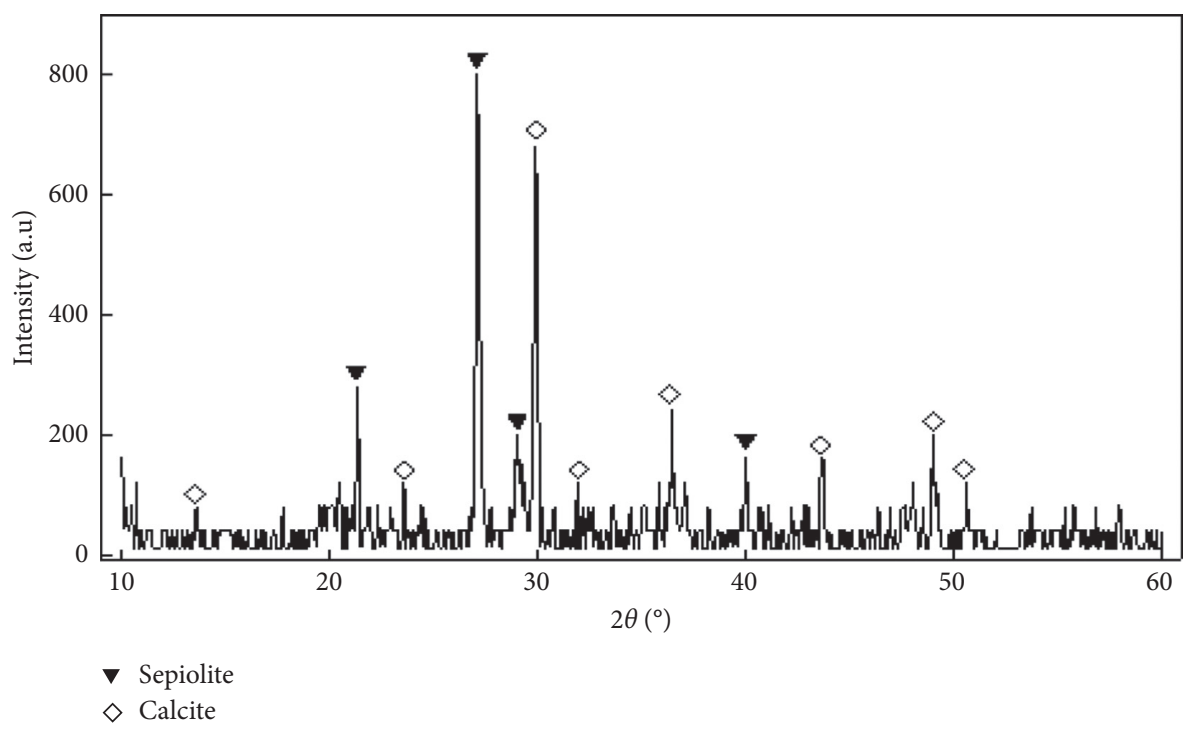

FIGURE 16: XRD pattern of sepiolite.

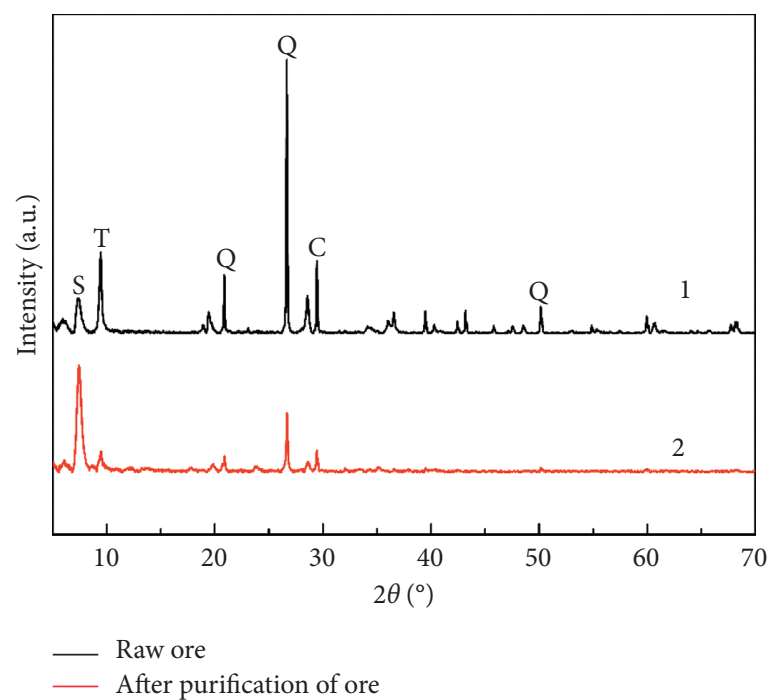

FIGURE 17: XRD phase analysis of sepiolite and purified sepiolite (1: raw ore; 2: purification of sepiolite; S: sepiolite; T: talc; Q; quartz; C: calcite).

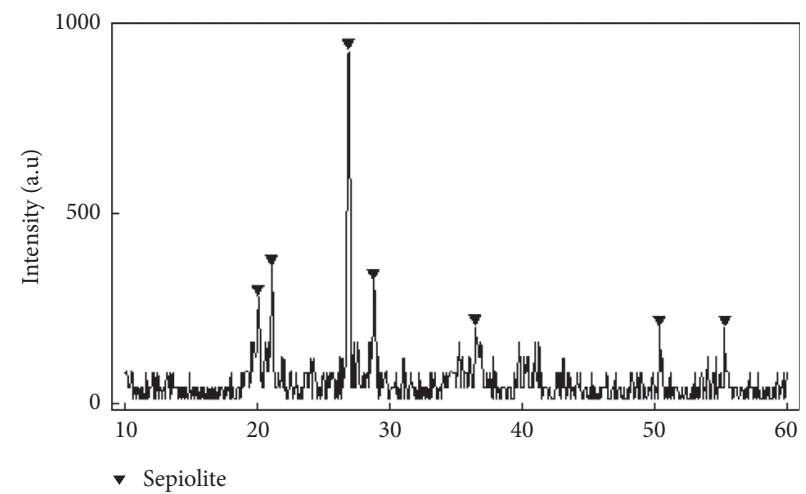

FIGURE 18: XRD pattern of the modified sepiolite. 


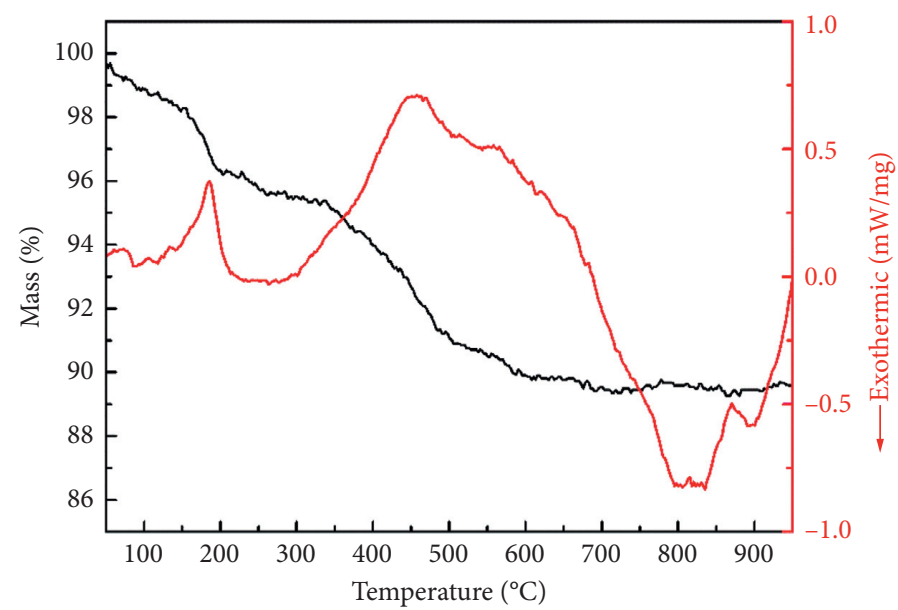

Figure 19: Test result.

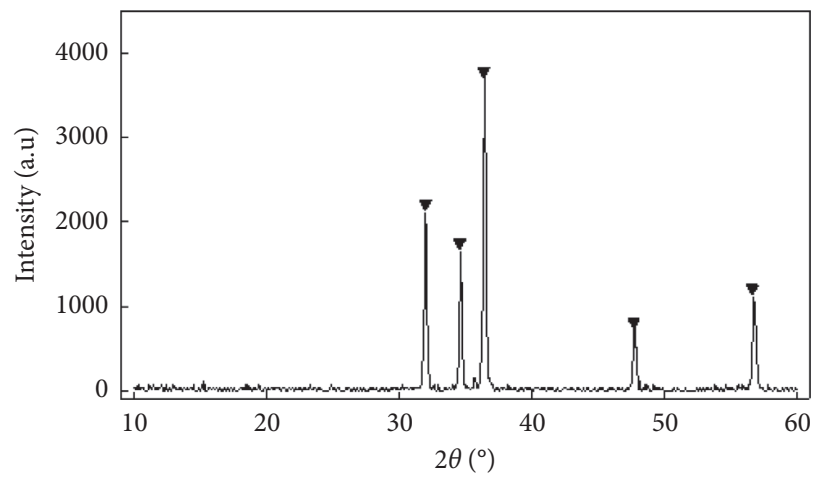

$\checkmark \mathrm{ZnO}$

Figure 20: XRD pattern of $\mathrm{ZnO}$.

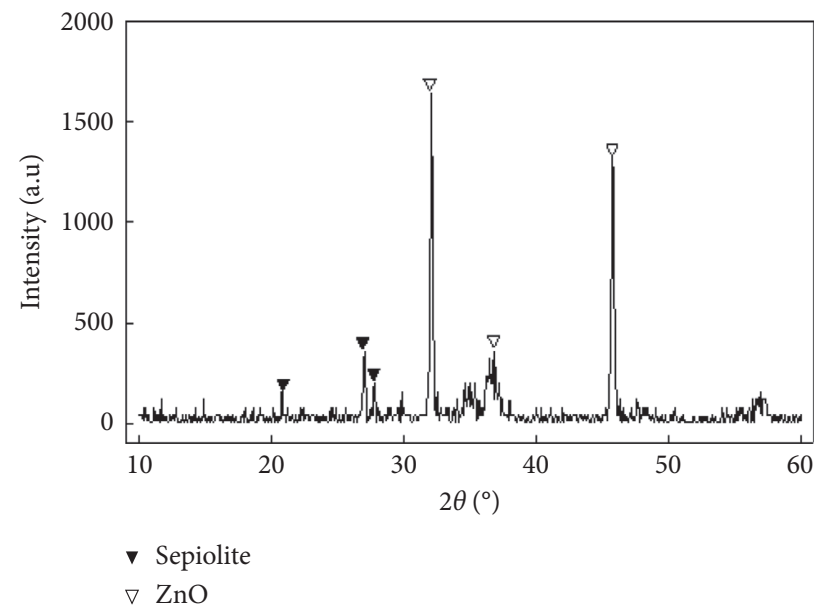

FIgURE 21: XRD pattern of the $\mathrm{ZnO} /$ sepiolite composite prepared by the sol-gel method.

4.5. Reaction Mechanism. When zinc oxide, as a semiconductor photocatalyst, is exposed to ultraviolet light, the valence band electrons of zinc oxide are excited to transition to the conduction band; thus, holes $\left(h_{V B}^{+}\right)$are generated in the valence band and photogenerated electron $\left(e_{C B}^{-}\right)$pairs are generated in the conduction band. In the solution, $h_{V B}^{+}$and $e_{C B}^{-}$can react with water and oxygen in a series of reactions, generates hydroxyl radical $(. \mathrm{OH})$ and other strong oxidation radicals, which oxidizes and degrades organic matter thoroughly and mineralizes into inorganic small molecules. The reaction steps are as follows: 


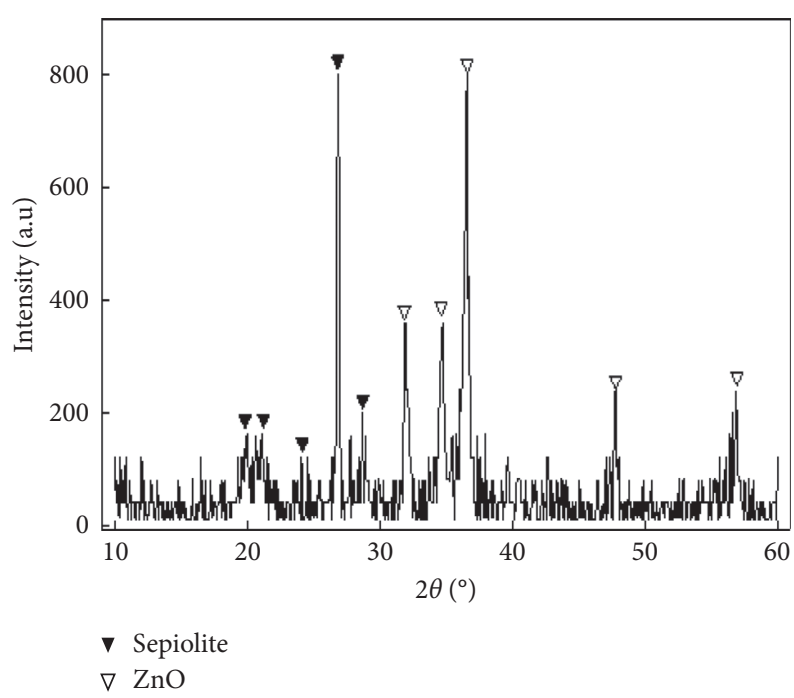

FIGURE 22: XRD pattern of the $\mathrm{ZnO} /$ sepiolite composite prepared by the hydrothermal reduction method.

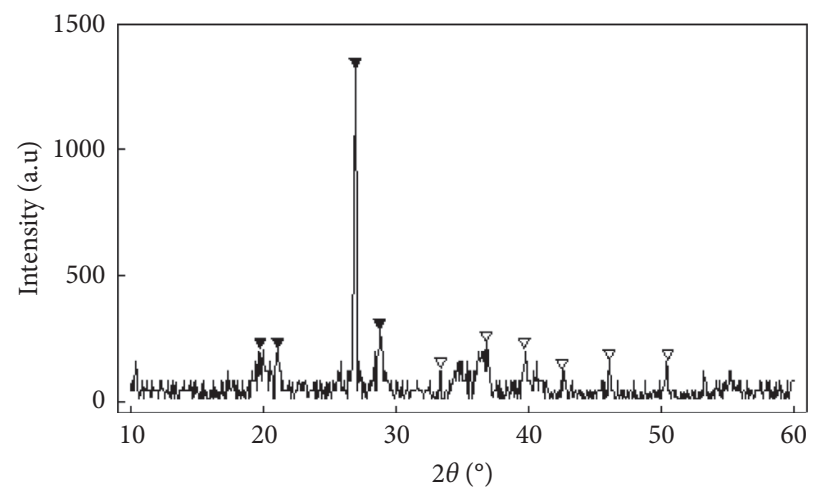

$\checkmark$ Sepiolite

$\nabla \mathrm{ZnO}$

FIGURE 23: XRD pattern of the $\mathrm{ZnO} /$ sepiolite composite prepared by the hydrolytic precipitation method.

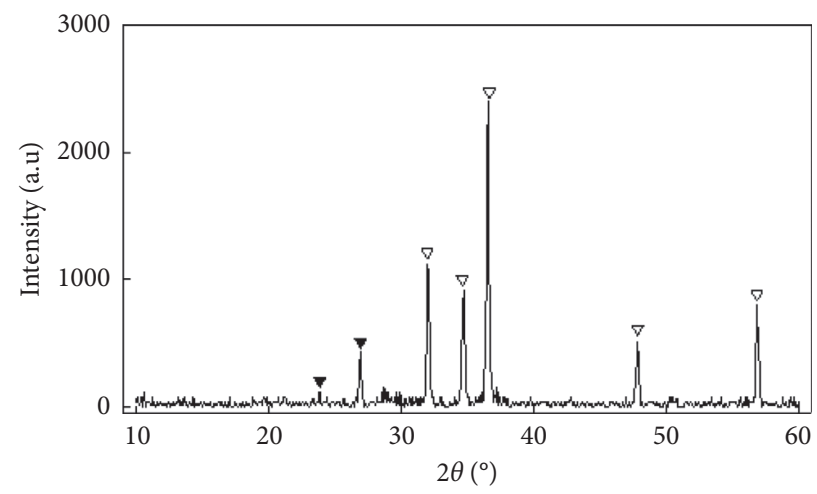

$\checkmark$ Sepiolite

$\nabla \mathrm{ZnO}$

FIGURE 24: XRD pattern of the $\mathrm{ZnO} /$ sepiolite composite prepared by the powder sintering method. 


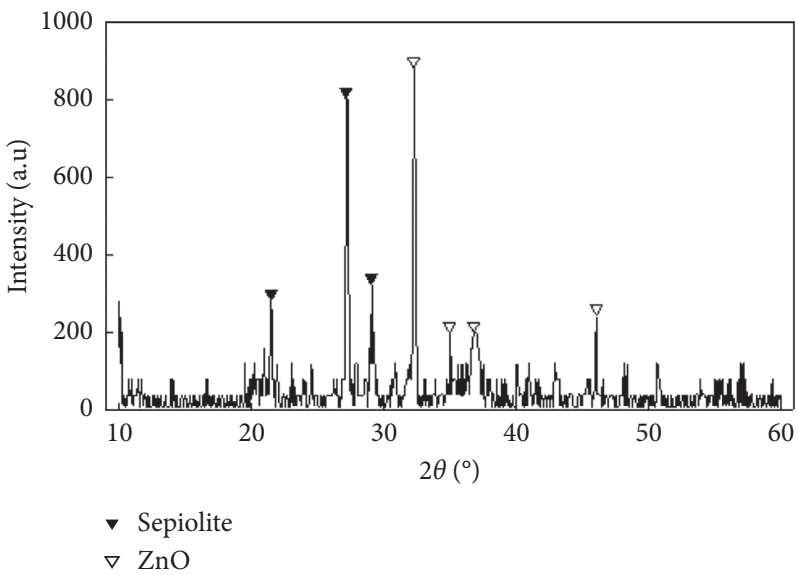

FIGURE 25: XRD pattern of the $\mathrm{ZnO}$ /sepiolite composite prepared by the impregnation-reduction method.

TABle 2: Characteristics of the $\mathrm{ZnO} /$ sepiolite composites obtained by the five different methods.

\begin{tabular}{ccc}
\hline Method & SEM & Infrared spectroscopy \\
\hline Sol-gel & $\begin{array}{c}\text { The sepiolite is coated by a } \\
\text { layer of a gelatinous material } \\
\text { with a large load and even } \\
\text { distribution. }\end{array}$ & $\begin{array}{c}\text { In the } 400-600 \mathrm{~cm}^{-1} \text { region, } \\
\text { the variation range of the } \\
\text { characteristic absorption } \\
\text { peaks is small. }\end{array}$
\end{tabular}

The sepiolite is coated by a In the $400-600 \mathrm{~cm}^{-1}$ region, Hydrothermal layer of a crystalline material the variation range of the reduction

Hydrolytic precipitation

Powder sintering Impregnationreduction with a large load and uneven distribution.

The sepiolite is coated by a layer of fine particles with a

large load and uneven distribution.

The sepiolite is coated by a layer of fine, evenly distributed particles with a moderate load.

The sepiolite is coated by a In the $400-600 \mathrm{~cm}^{-1}$ region, layer of small loose particles the variation range of the distribution that undergo partial agglomeration. characteristic absorption peaks is high.

In the $400-600 \mathrm{~cm}^{-1}$ region, the variation range of the characteristic absorption peaks between the two groups is small.

In the $400-600 \mathrm{~cm}^{-1}$ region, the variation range of the characteristic absorption peaks is large.

characteristic absorption peaks between the two groups is average. with a large load and uniform
The diffraction peak of zinc oxide is weak and exhibits a poor shape.

The diffraction peak of zinc oxide is strong and exhibits a good shape.

The diffraction peak of zinc oxide is strong and exhibits a good shape. A part of the peak indicates the occurrence of a passivation process.
Conclusion

Zinc oxide is successfully supported on sepiolite in the gel state with a large load, uniform particle distribution, and high degree of crystallinity.

Zinc oxide is successfully supported on sepiolite in the crystal form with a large load, uneven distribution, and high degree of crystallinity.

Zinc oxide is successfully supported on sepiolite in the form of fine particles with a large load, uneven distribution, and low degree of crystallinity.

Zinc oxide is successfully supported on sepiolite with a moderate load, uniform distribution, and high degree of crystallinity.

Zinc oxide is successfully supported on sepiolite in the form of loose particles with a large load, uniform distribution, high degree of crystallinity, and high degree of agglomeration.

$$
\begin{gathered}
\mathrm{ZnO}+h v \longrightarrow e_{C B}^{-}+h_{V B}^{+} \\
\mathrm{O}_{2}+e_{C B}^{-} \longrightarrow \mathrm{O}_{2}^{-} \\
\left(\mathrm{H}_{2} \mathrm{O} \Leftrightarrow \mathrm{H}^{+}+\mathrm{OH}^{-}\right)+h v_{V B}^{+} \longrightarrow \cdot \mathrm{OH}+\mathrm{H}^{+} \\
\mathrm{O}_{2}^{--}+\mathrm{H}^{+} \longrightarrow \mathrm{HO}_{2} \\
2 \mathrm{HO}_{2} \longrightarrow \mathrm{H}_{2} \mathrm{O}_{2}+\mathrm{O}_{2}
\end{gathered}
$$

$$
\begin{gathered}
\mathrm{H}_{2} \mathrm{O}_{2}+e^{-} \longrightarrow \cdot \mathrm{OH}+\mathrm{OH}^{-} \\
\mathrm{MB}+\cdot \mathrm{OH} \longrightarrow \text { degradation product }+\mathrm{H}_{2} \mathrm{O}
\end{gathered}
$$

. $\mathrm{OH}$ is the most important oxidant for $\mathrm{MB}$ degradation, and the production of $\cdot \mathrm{OH}$ is directly related to the production of $h_{V B}^{+}$. Under UV irradiation, electron-hole pairs are generated on the $\mathrm{ZnO}$ surface. At the same time, when the concentration of $\mathrm{OH}$ - ions in the solution increases, more $\mathrm{OH}$ - will be oxidised to $\mathrm{OH}$ by the holes generated on 


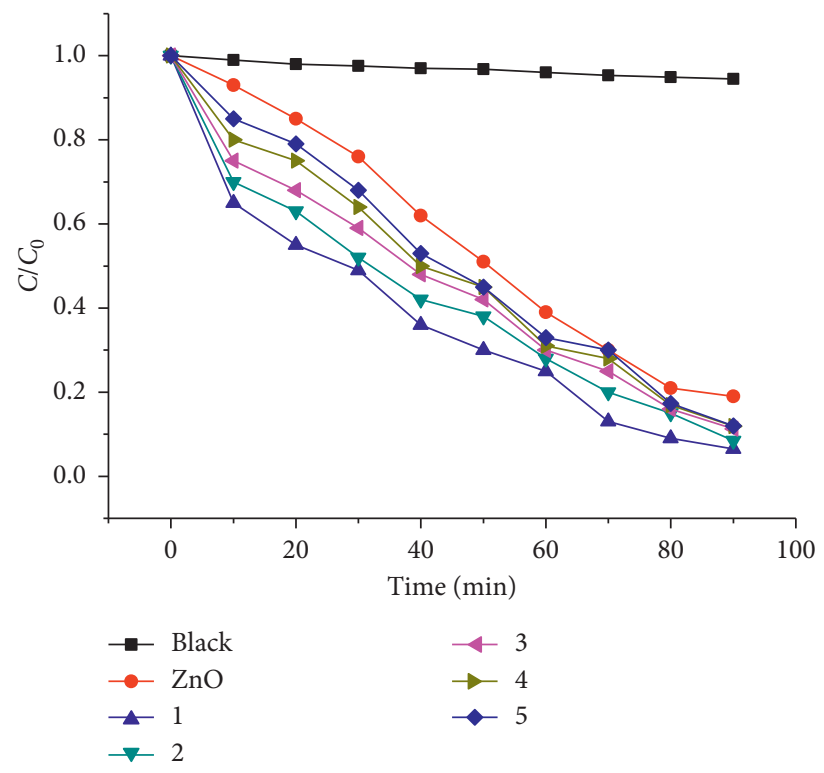

Figure 26: MB concentration plotted as a function of the exposure time for the $\mathrm{ZnO}$ /sepiolite composites prepared by five different methods (1: sol-gel; 2: hydrothermal reduction; 3: hydrolytic precipitation; 4: powder sintering; 5: impregnation-reduction).

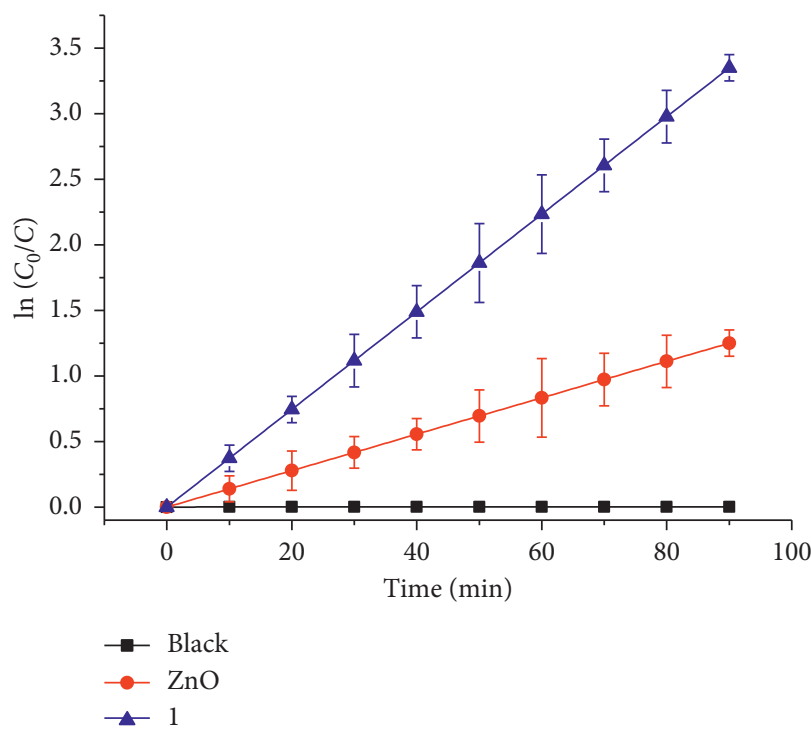

Figure 27: $\operatorname{Ln}(\mathrm{C})_{0} /(\mathrm{C})$ plotted as a function of the degradation time $(t)$ for various samples subjected to UV light irradiation (1: $\mathrm{ZnO} /$ sepiolite composites).

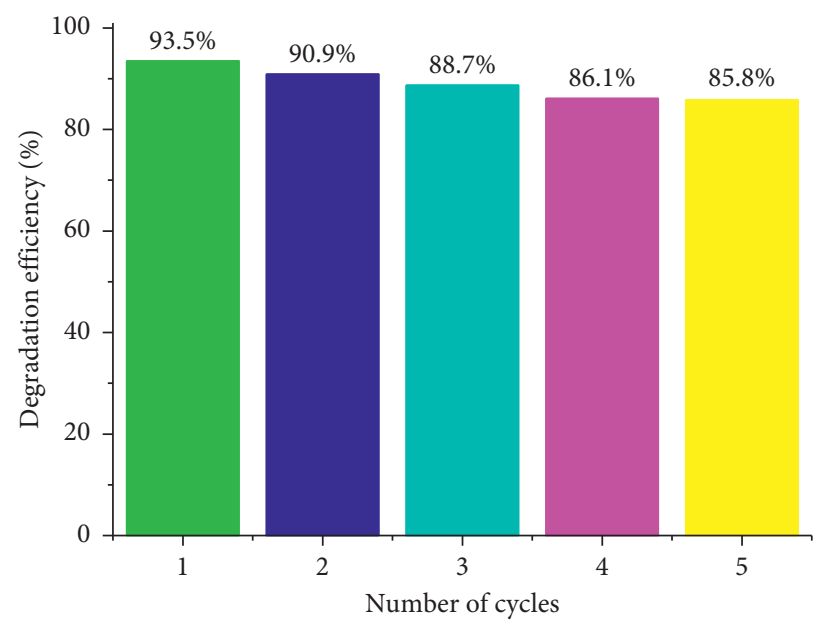

FIGURE 28: MB photodegradation efficiencies measured during the five treatment cycles. 


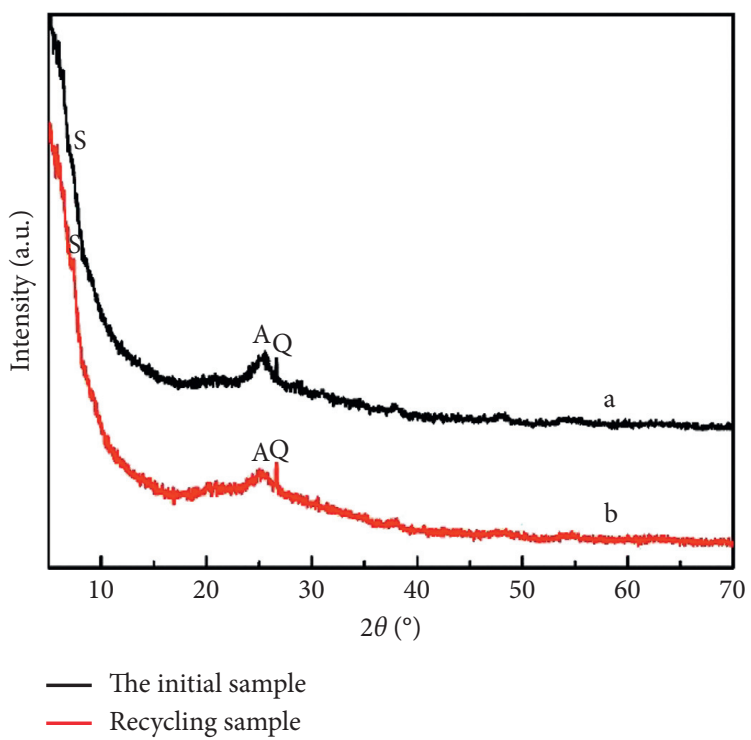

FIGURE 29: XRD phase analysis Atlas of composites (a: initial sample; b: recycling sample after the cycle; S: sepiolite; A: ZnO; Q: quartz).

the photocatalyst surface. The increase of $\cdot \mathrm{OH}$ concentration is conducive to the improvement of the treatment effect. Therefore, the $h_{V B}^{+}$increased yield or the addition of cocatalyst (strong oxidant) is beneficial to improve the processing capacity of photocatalytic materials. Meanwhile, in the process of degrading $\mathrm{MB}, \mathrm{MB}$ can be used as a photosensitizer. Under ultraviolet light irradiation, the system is photosensitized, and the ground-state oxygen is irradiated to produce singlet oxygen $\left({ }^{1} \mathrm{O}_{2}\right)$ :

$$
\begin{aligned}
& \text { sensitizer-hv-sensitizer } \mathrm{T} 1 \\
& \text { sensitizer } \mathrm{T} 1+\mathrm{O}_{2} \text { (groundstate) - energytransfer- sensitizer }+{ }^{1} \mathrm{O}_{2}
\end{aligned}
$$

\section{Conclusion}

In this study, sepiolite was used as a catalytic substrate to synthesise novel $\mathrm{ZnO}$ /sepiolite composites by five different methods, and the catalytic efficiencies of the produced materials were determined by investigating the photocatalytic degradation of $\mathrm{MB}$ dye. The microstructures of these materials were observed, their photocatalytic properties and stabilities were evaluated, and their reaction kinetics was examined. The obtained conclusions were summarised as follows:

(1) After the thermal acid treatment, carbonate impurities were removed from the sepiolite surface, while the sizes of sepiolite pores and channels as well as the specific surface area and catalytic activity of sepiolite increased.

(2) The $\mathrm{ZnO} /$ sepiolite composites prepared by different methods had different loading forms and loads. When the sol-gel method was used, a zinc oxide layer was coated onto the sepiolite surface in the form of a gel with a relatively large load and uniform distribution. When the composite was prepared by the hydrothermal reduction method, zinc ions were loaded onto the sepiolite surface in the form of crystals and then oxidised to form unevenly distributed zinc oxide particles. When the composite material was prepared by the hydrolytic precipitation method, zinc ions precipitated into zinc hydroxide species attached to the sepiolite surface and then decomposed into zinc oxide species under high-temperature conditions. Therefore, the loaded particles exhibited microspherical shapes and a relatively large load with an uneven distribution. The powder sintering method resulted in a composite material with a uniform particle distribution using a simple technique. Finally, when the composite was prepared by the impregnation-reduction method, loose zinc oxide particles were uniformly distributed across the sepiolite surface and partially agglomerated. Therefore, the sol-gel method is superior to the hydrothermal reduction, hydrolytic precipitation, powder sintering, and impregnation-reduction methods.

(3) The photocatalytic degradation of $\mathrm{MB}$ by the $\mathrm{ZnO} /$ sepiolite composite prepared by the sol-gel method represented a quasi-first-order reaction. In addition, this material demonstrated excellent chemical stability and reusability.

The results of this study revealed that the sol-gel method could be used to prepare photocatalytic composite materials 
with excellent performance characteristics, which was consistent with their good photocatalytic properties observed during pollutant degradation. Thus, these findings can provide a basis for the development, preparation, and application of novel photocatalysts. In future works, the photocatalytic performance of composite materials will be enhanced by controlling the reaction conditions to expand the application range of $\mathrm{ZnO} /$ sepiolite composites.

\section{Data Availability}

The experimental data used to support the findings of this study are available from the corresponding author upon request.

\section{Conflicts of Interest}

The authors declare no conflicts of interest related to the publication of this study.

\section{Authors' Contributions}

Chao Li was responsible for the writing of the original draft, validation, and visualization. Huijuan Li was responsible for the experiment and data curation. Guicheng $\mathrm{He}$ was responsible for the review and editing. Zhiwu Lei was responsible for the supervision. Wenyuan $\mathrm{Wu}$ was responsible for the cartography and documentation.

\section{Acknowledgments}

This study was supported by the National Natural Science Foundation of China (51974163) and the Key Scientific Research Foundation of Hunan Provincial Education Department (18A248). Thanks are due to the Hunan Province \& Hengyang City Engineering Technology Research Center for Disaster Prediction and Control on Mining Geotechnical Engineering (2019TP2070) for providing experimental platform support.

\section{References}

[1] S. N. Frank and A. J. Bard, "Heterogeneous photocatalytic oxidation of cyanide and sulfite in aqueous solutions at semiconductor powders," The Journal of Physical Chemistry, vol. 81, no. 15, pp. 1484-1488, 1977.

[2] C.-G. Tsai and W. J. Tseng, "Preparation of $\mathrm{TiN}_{-} \mathrm{TiO}_{2}$ composite nanoparticles for organic dye adsorption and photocatalysis," Ceramics International, vol. 46, no. 10, pp. 14529-14535, 2020.

[3] C. Adler, D. Mitoraj, I. Krivtsov, and R. Beranek, "On the importance of catalysis in photocatalysis: triggering of photocatalysis at well-defined anatase $\mathrm{TiO}_{2}$ crystals through facetspecific deposition of oxygen reduction cocatalyst," Journal of Chenical Physics, vol. 152, no. 24, 2020.

[4] C. A. Walenta, M. Tschurl, and U. Heiz, "Introducing catalysis in photocatalysis: what can be understood from surface science studies of alcohol photoreforming on $\mathrm{TiO}_{2}$," Journal of Physics-Condensed Matter, vol. 31, no. 47, 2019.

[5] E. Basturk, M. Ișık, and M. Karatas, "Removal of aniline (Methylene Blue) and azo (Reactive Red 198) dyes by photocatalysis via nano $\mathrm{TiO}_{2}$," Desalination and Water Treatment, vol. 143, pp. 306-313, 2019.

[6] B. Szczepanik, "Photocatalytic degradation of organic contaminants over clay- $\mathrm{TiO}_{2}$ nanocomposites: a review," Applied Clay Science, vol. 141, pp. 227-239, 2017.

[7] S. Miaralipour, D. Friedmann, J. Scott, and R. Amal, " $\mathrm{TiO}_{2} /$ porous adsorbents: recent advances and novel applications," Journal of Hazardous Materials, vol. 341, pp. 404-423, 2018.

[8] C. Gao, T. Wei, Y. Zhang et al., "A photoresponsive rutile $\mathrm{TiO}_{2}$ heterojunction with enhanced electron-hole separation for high-performance hydrogen evolution," Advanced Materials, vol. 31, no. 8, pp. 1806596-1806602, 2019.

[9] Y. Cui, Z. Zhang, B. Li et al., "Ultrasound assisted fabrication of $\mathrm{AgBr} / \mathrm{TiO}_{2}$ nano-tube arrays photoelectrode and its enhanced visible photocatalytic performance and mechanism for detoxification of 4-chlorphenol," Separation and Purification Technology, vol. 197, pp. 189-196, 2018.

[10] L. Zhou, D. Jiang, X. Du et al., "Femtomolar sensitivity of bisphenol A photoelectrochemical aptasensor induced by visible light-driven $\mathrm{TiO}_{2}$ nanoparticle-decorated nitrogendoped graphene," Journal of Materials Chemistry B, vol. 4, no. 37, pp. 6249-6257, 2016.

[11] J. Shi, Y. Kuwahara, T. An, and H. Yamashita, "The fabrication of $\mathrm{TiO}_{2}$ supported on slag-made calcium silicate as low-cost photocatalyst with high adsorption ability for the degradation of dye pollutants in water," Catalysis Today, vol. 281, pp. 21-28, 2017.

[12] G. Zheng, W. Shang, L. Xu, S. Guo, and Z. Zhou, "Enhanced photocatalytic activity of $\mathrm{ZnO}$ thin films deriving from a porous structure," Materials Letters, vol. 150, pp. 1-4, 2015.

[13] S. J. Jian, W. S. Yang, and W. S. Lin, "Preparation and photocatalytic activity of $\mathrm{ZnO}$ nanofibers," Modern Chemical Industry, vol. 35, no. 10, pp. 84-88, 2015.

[14] M. Wang, J. Xu, T. Sun, Y. Tang, G. Jiang, and Y. Shi, "Facile photochemical synthesis of hierarchical cake-like $\mathrm{ZnO} / \mathrm{Ag}$ composites with enhanced visible-light photocatalytic activities," Materials Letters, vol. 219, pp. 236-239, 2018.

[15] Y. Liu, S. Wei, and W. Gao, "Ag/ZnO heterostructures and their photocatalytic activity under visible light: effect of reducing medium," Journal of Hazardous Materials, vol. 287, pp. 59-68, 2015.

[16] L. Muñoz-Fernandez, A. Sierra-Fernandez, O. Milošević, and M. E. Rabanal, "Solvothermal synthesis of $\mathrm{Ag} / \mathrm{ZnO}$ and $\mathrm{Pt} /$ $\mathrm{ZnO}$ nanocomposites and comparison of their photocatalytic behaviors on dyes degradation," Advanced Powder Technology, vol. 27, no. 3, pp. 983-993, 2016.

[17] S. Heinonen, J.-P. Nikkanen, and H. Hakola, "Effect of temperature and concentration of precursors on morphology and photocatalytic activity of zinc oxide thin films prepared by hydrothermal route," IOP Conference Series: Materials Science and engineering, 3rd International Conference on Competitive Materials and Technology Processes, IC-CMTP Oct, 2014, vol. 123, Article ID 012030, 2016.

[18] M. Hwangbo, E. C. Claycomb, Y. Liu, T. E. G. Alivio, S. Banerjee, and K.-H. Chu, "Effectiveness of zinc oxideassisted photocatalysis for concerned constituents in reclaimed wastewater: 1,4-Dioxane, trihalomethanes, antibiotics, antibiotic resistant bacteria (ARB), and antibiotic resistance genes (ARGs)," Science of the Total Environment, vol. 649, no. 1, pp. 1189-1197, 2019.

[19] O. Yukhnovets, A. A. Semenova, and E. A. Levkevich, "Zincoxide hierarchical nanostructures for photocatalysis," Journal of Physics: Conference Series, vol. 993, Article ID 012009, 2018. 
[20] P. Sriprom, S. Prothanatt, A. Neramittagapong, and S. eramittagapong, "Parameter screening for the important factors influencing the aniline removal by photocatalysis over supported zinc oxide catalyst," Advanced Materials Research, vol. 931-932, pp. 37-41, 2014.

[21] L. T. T. Nguyen and L. T. H. Nguyen, "Preparation,characterization and Photocatalytic Activity of La-Doped Zinc Oxide nanoparticles," Materials, vol. 12, no. 8, p. 1195, 2019.

[22] R. C. Pawar, D. Cho, and S. L. Caroline, "Fabrication of nanocomposite photocatalysts from zinc oxide nanostructures and reduced graphene oxide," Current Applied Physics, vol. 7, no. 20, pp. 50-57, 2013.

[23] L. Zhang, D. Zhu, H. He, Q. Wang, L. Xing, and X. Xue, "Enhanced piezo/solar-photocatalytic activity of $\mathrm{Ag} / \mathrm{ZnO}$ nanotetrapods arising from the coupling of surface plasmon resonance and piezophototronic effect," Journal of Physics and Chemistry of Solids, vol. 102, pp. 27-33, 2017.

[24] X. Hou, " $\mathrm{ZnO} / \mathrm{Ag}$ heterostructured nanoassemblies: wetchemical preparation and improved visible-light photocatalytic performance," Materials Letters, vol. 139, pp. 201204, 2015.

[25] Q. Deng, H. Tang, G. Liu et al., "The fabrication and photocatalytic performances of flower-like Ag nanoparticles/ $\mathrm{ZnO}$ nanosheets-assembled microspheres," Applied Surface Science, vol. 331, pp. 50-57, 2015.

[26] X. Zhang, Y. Wang, F. Hou et al., "Effects of Ag loading on structural and photocatalytic properties of flower-like $\mathrm{ZnO}$ microspheres," Applied Surface Science, vol. 391, pp. 476-483, 2017.

[27] M. Akkari, P. Aranda, C. Belver, J. Bedia, A. Ben Haj Amara, and E. Ruiz-Hitzky, "Reprint of $\mathrm{ZnO} /$ sepiolite heterostructured materials for solar photocatalytic degradation of pharmaceuticals in wastewater," Applied Clay Science, vol. 160, pp. 3-8, 2018.

[28] Y. Sun, G. Sun, Y. Xu et al., "In situ stabilization remediation of cadmium contaminated soils of wastewater irrigation region using sepiolite," Journal of Environmental Sciences, vol. 24, no. 10, pp. 1799-1805, 2012.

[29] A. V. Agafonov, A. A. Redozubov, V. V. Kozik, and A. S. Kraev, "Photocatalytic activity of titania nanopowders prepared by a sol-gel process at various pHs," Russian Journal of Inorganic Chemistry, vol. 60, no. 8, pp. 906-912, 2015.

[30] Z. Xu, Y. N. Zhu, Z. Y. Pang, and M. Ge, "Sol-gel preparation and properties of electroconductive $\mathrm{Sn}$-Al co-doped $\mathrm{ZnO}$ coated $\mathrm{TiO}_{2}$ whisker and its applications in textiles," Materials Science in Semiconductor Processing, vol. 124, 2021.

[31] R. Fan, M. Kyodo, L. Tan et al., "Preparation and application of $\mathrm{Cu} / \mathrm{ZnO}$ catalyst by urea hydrolysis method for lowtemperature methanol synthesis from syngas," Fuel Processing Technology, vol. 167, pp. 69-77, 2017.

[32] Q. Ma, X. M. Han, and K. Lv, "Ultrasound-enhanced preparation and photocatalytic properties of graphene- $\mathrm{ZnO}$ nanorod composite," Separation and Purification Technology, vol. 259, 2021.

[33] F. Giovannelli, A. Ngo Ndimba, P. Diaz-Chao et al., "Synthesis of $\mathrm{Al}$ doped $\mathrm{ZnO}$ nanoparticles by aqueous coprecipitation," Powder Technology, vol. 262, pp. 203-208, 2014.

[34] D. Raoufi, "Synthesis and microstructural properties of $\mathrm{ZnO}$ nanoparticles prepared by precipitation method," Renewable Energy, vol. 50, pp. 932-937, 2013.

[35] C. Chen, P. Liu, and C. Lu, "Synthesis and characterization of nano-sized $\mathrm{ZnO}$ powders by direct precipitation method," Chemical Engineering Journal, vol. 144, no. 3, pp. 509-513, 2008.
[36] C. Jeong, M. J. Hyun, and Y.-W. Suh, "Activity of coprecipitated $\mathrm{CuO} / \mathrm{ZnO}$ catalysts in the decomposition of dimethylhexane-1,6-dicarbamate," Catalysis Communications, vol. 70, pp. 34-39, 2015.

[37] M. F. Ehsan, S. Bashir, S. Hamid et al., "One-pot facile synthesis of the $\mathrm{ZnO} / \mathrm{ZnSe}$ heterostructures for efficient photocatalytic degradation of azo dye," Applied Surface Science, vol. 30, no. 459, pp. 194-200, 2018.

[38] S. El-Nahas, M. S. Abd El-sadek, H. M. Salman, and M. M. Elkady, "Controlled morphological and physical properties of $\mathrm{ZnO}$ nanostructures synthesized by domestic microwave route," Materials Chemistry and Physics, vol. 258, 2021.

[39] C. Z. Chen and Z. W. Zhou, "Preparation of nano-sized zinc oxide and its mid-infrared, UV-visible light absorption characteristics," Function Materials, vol. 35, no. 1, pp. 97-98, 2004. 